\title{
REFLEXIONES SOBRE LA PROCEDENCIA Y EVOLUCIÓN DEL "RITMO" EN LA MONODIA LITÚRGICA Y POLIFONIA MEDIEVAL (y II)
}

José V. González Valle

CSIC

\section{Resumen:}

Continúan las reflexiones iniciadas en la primera parte de este artículo (AnM 62, 2007, 39-74) sobre la procedencia y evolución del ritmo en la música de Occidente, surgidas en la lectura de destacados escritos de música desde la antigüedad cristiana hasta la configuración de la notación mensural hacia la se gunda mitad del siglo XIII. Esta segunda parte se funda en los escritores latinos de música, desde San Agustín hasta el siglo xIII.

\section{Palabras Clave:}

Monodia litúrgica. Polifonía medieval. Ritmo. Metro. Acento. Cuantidad. Mensura. Música-lenguaje. Escritores latinos.

\section{Abstract}

This paper follows the contents of its pre vious part (AnM 62, 2007, 39-74), dealing with the provenance and evolution of rhythm in Western music. The questions here exposed, come from reading noteworthy writings on music from the Christian Antiquity till the shaping of mensural notation, towards the second half of the $13^{\text {th }}$ century. This second part is based on Latin writers of music, from Augustine till the $13^{\text {th }}$ century.

Key Words:

Liturgical Monody. Medieval Polyphony. Rhythm. Metre. Accent. Quantity. Mensura. Music-language. Latin writers.

En esta segunda parte ${ }^{1}$, continúan las reflexiones sobre la procedencia y evolución del ritmo en la música de Occidente, surgidas de la lectura de destacados escritos de música desde la antigüedad cristiana hasta la configuración de la notación mensural hacia la segunda mitad del siglo XIII. Consciente de que el

1 Véase la primera parte de este trabajo: -ConzÁlez VALLE, José Vicente: "Reflexiones sobre la procedencia y evolución del "ritmo" en la monodia litúrgica y polifonía medieval (I)", en Anuario Musical, 62 (2007), pp. 39-74. 
pasado ayuda a entender mejor el presente, he indagado cómo entienden, explican y expresan el ritmo no sólo los teóricos de música coetáneos de las composiciones o compositores, sino también los de épocas anteriores y, así, retrospectivamente, he reunido la presente selección de textos.

Como hemos visto en la primera parte de este trabajo, lenguaje y música han caminado íntimamente relacionados. Los escritores de la antigüedad greco-romana (Platón, Aristóteles, Cicerón, Horacio, M. F. Quintiliano) centraron su atención en el ritmo del v erso y de la prosa, fundándose en determinadas cualidades inherentes al lenguaje como la cuantidad silábica o el acento. La agrupación y orden de las sílabas (tiempo largo, breve) o pies en el verso, como también en la prosa, dictaban el ritmo (atado/verso o suelto/discurso oratorio). De un modo análogo a la "música armónica" o sistema fundado en diferencias interválicas de los sonidos, la "música rítmica" y "música métrica" son sistemas configurados a partir de otras diferencias del sonido como la cuantidad e intensidad. Dichas teorías sobre el fundamento del ritmo siguieron transmitiéndose en la antigüedad tardía a tra vés de escritores de música como Arístides Quintiliano (siglo II) o, posteriormente, Marciano Capella (siglo Iv), San Agustín (siglo IV), hasta el siglo XVI (Franchino Gafurius, Francisco Salinas).

Entre las diferencias cualitati vas inherentes al lenguaje, han tenido a lo lar go del tiempo un papel preponderante la cuantidad silábica ("per tempora [...] si pro longa syllaba brevis ponatur, aut pro brevi longa" ["por tiempos [...] si se pone una sílaba bre ve por una long a, o una long a por una bre ve"] ${ }^{2}$, y el acento silábico ("per tonos, si accentus in alia syllaba commutetur" ["por los sonidos, si se cambia de sílaba el acento"]) $)^{3}$.

Aunque cuantidad (breve o longa) y acento (intensivo o leve) son elementos prosódicos diferentes, se asemejan de tal manera respecto a su función idiomática y musical ( sílaba/sonido: agudo o gra ve, largo o breve, intenso o leve, signo prosódico o neuma ${ }^{4}$ musical: virga, punto), que no es fácil establecer entre ellos una diferencia clara. Menos aún, en latín, ya que los escritores latinos heredaron y tradujeron dichos términos de la prosodia griega. De ahí, el continuo y controertido debate mantenido por filólogos y musicólogos sobre la poesía o música métrica (cuantidad, metro) y rítmica (acento, número) medieval. En este sentido, se piensa que la investigación musicológica (mensuralista) sobre las notaciones musicales debería releer los teóricos de música de la antigüedad tardía y edad media (ss. IV-XIII), teniendo más en cuenta la línea de investigación del canto gregoriano iniciada, en el sigloxix, por la escuela de Solesmes (Guéranger, Pothiers, Mocquereau), que ha estudiado histórica y sistemáticamente el ritmo musical, partiendo del "acento idiomático".

El lenguaje dispone de otros elementos para materializar el ritmo, como la articulación "aritmética" de las sílabas o palabras, basándose en el ictus (golpe, acento), en cuanto “impulso ordenante”, gracias al cual - al hablar, recitar o cantar-, es posible también numerarcontar y ogganizar las sílabas, combinando proporcionalmente grupos binarios con ternarios (“prudénter / atténdens”: x’xx / x’xx [3/2, sesquiáltera];

2 -San Isidoro de Sevilla: "De Musica”, en Etymologiae, i, 32, 4. Madrid, Biblioteca de Autores Cristianos 433, 1982, p. 325. En adelante citado: "BAC 433, p.".

3 -SAn Isidoro de Sevilla: op. cit., ibid.

4 Cfr. -Bernhard, Michael: “Accentus” y “Acumen”, en Lexikon Musicum Latinum Medii Aevi. Fascículo 2. Munich, Verlag der Bayerischen Akademie der Wissenschaften, 1995, columnas 20-23 y 30-32, respectivamente. 
“Laudáte / Dóminum // ómnes / géntes": x'xx / 'xxx // 'xx / ’xx [2+3/2+2=5/4, sesquicuarta]) $\quad{ }^{5}$. Se dice, que el acento es anima vocis, ya que no sólo sirv e para dar vida al lenguaje, diferenciando el tono o intensidad de las sílabas, sino que e xiste otra razón aún más íntima, esencialmente ligada a las le yes naturales del lenguaje, como fundir en un todo vivo las sílabas de una misma palabra y, al mismo tiempo, ayudar al oído a distinguir unas palabras de otras dentro del discurso en prosa o en v erso. El acento es una fuerza centrípeta ${ }^{6}$, que agrupa todas las sílabas de una misma palabra alrededor de una de ellas, como punto central o fuerza de atracción. Las di versas sílabas, que forman una palabra, no tienen la misma importancia al pronunciar ${ }^{7} \mathrm{o}$ articular el lenguaje.

Ritmo y metro se asemejan, en que ambos se amparan en conceptos matemáticos como número/ ritmo (aritmética: multitud, adición o agregación de unidades) ocuantidad/metro (geometría: magnitud, división o multiplicación de figuras), como hemos observado en anteriores escritores latinos y veremos más adelante. Los teóricos hablan constantemente de cuantidad y acento. Cuantidad es pronunciación silábica larga o bre ve, el acento, en cambio, no es lar go o bre ve por naturaleza; originalmente, al parecer, era más bien bre ve que largo y, aunque, al principio, pudiera haber sido "melódico" (sonido agudo o grave), terminó siendo "dinámico". Los antiguos no ignoraban la fuerza del acento dinámico. Cuando había que observ arlo en la simple recitación o en las "melodías" silábicas (salmos, lecturas, versículos, oraciones), lo indicaban gráficamente, como podemos observar en numerosos manuscritos antiguos.

No obstante, la procedencia y eolución de larítmica medieval sigue siendo un tema muy discutido y controvertido. Ya me referí anteriormente a esto. Se gún J. Wolf, la teoría de que, al vencer el acento silábico a la cuantidad, la poesía métrica se transformó en rítmica, es demasiado simple y no resuelve el meollo de la cuestión, aunque, en algunos casos, sucediera tal transformación como, por ejemplo, cuando los dímetros yámbicos ambrosianos (bre ve-longa+breve-longa / bre ve-longa+breve-longa) se convirtieron en v ersos octosílabos, basados en el acento silábico (x x' + x x' / x x' + x x': cuatro elevaciones o acentos por v erso, o "vier Hebigk eit Prinzip", se gún los filólogos medievalistas; como existen también hexámetros rítmicos). El fundamento lo puso SanAgustín en suPsalmus contra partem Donati, que, aunque fuesen para cantar, conscientemente no los compuso métricamente, sino que, para que el pueblo pudiera interpretarlos fácilmente, numeró las sílabas y dispuso las responsiones con los mismos acentos y la misma rima que elversillo. Lo determinante, para SanAgustín, fue la articulación, basada en el acento del lenguaje, y la cuenta del número de sílabas, siguiendo el principio de la salmodia hímnica $^{8}$. Conviene también recordar, que la gramática latina (Donato, siglo IV; Prisciano, siglo VI), como otras muchas disciplinas, se escribían y enseñaban en $\mathrm{v}$ ersos métricos y/o rítmicos, ya que, de

5 En la notación musical, losneumas (ligaturas) de dos, tres o cuatro notasp(es-2, podatus-2, clivis-2, torculus-3, scandicus3 , salicus-3, torculus resupinus-4, etc.) se asemejan a lospies métricos de dos, tres o cuatro sílabas firriquio-2, yambo-2, troqueo2, tríbraco-3, dáctilo-3, troqueo-3, proceleusmático-4, etc.).

6 -Georgiades, Thrasybulos: Nennen und Erklingen. Göttingen, Vandenhoeck \& Ruprecht, 1985, pp. 150, $173-174$.

7 -Pothier, Dom Joseph: Les mélodies grégoriennes. París, Stock Musique, 1980 (reedición a partir del original de Pothier Desclée Lefebvre, 1880), p. 149.

8 -Langosch, Karl: Lateinisches Mittelalter. Darmstadt, Wissenschaftliche Buchgessellschaft, 1969, p. 72. 
este modo, se memorizaba mejor. Alexander de Villa Dei redactó, el año 1199, su gramática latina en 2645 hexámetros 9 .

Algo semejante a la "transformación" de la poesía métrica en rítmica, aunque, en sentido contrario (acento en cuantidad), pudo producirse en el ritmo musical durante los "oscuros siglos" ( IX-XII) de la notación musical europea. Los conocidos modos rítmicos (primeras fórmulas estereotipadas "rítmicomusicales" cuantitativas conocidas) pueden retrotraernos, a lo sumo, hasta el tránsito del siglo XII al XIII, según la investigación histórico-musical. Aunque existen innumerables manuscritos de música monódica (trovadores, cantig as, etc.) y polifónica en notación neumática cursi va y cuadrada, muchos de ellos copiados tardíamente, a finales del siglo XIV, que no se someten a dicha rítmica modal (cuantitativa). J. Wolf ${ }^{10}$ planteaba la siguiente cuestión:

"en los modos [rítmicos], tuv o que tratarse de una práctica lar gamente ejercitada, pues, si no, los teóricos seguramente hubieran dedicado al tema muchas más palabras de las que han dejado escritas. De su relación con la antigüedad es consciente el siglo XIII y, como prueba, está el tratado de Walter Odington. En el siglo XII, en Francia, la forma de secuencia latina, que ofrecen las prosas de Adam de San Víctor, abrió el camino del desarrollo a la práctica modal [rítmica]".

Lo único verificable es, que la notación musical terminó desarrollándose o racionalizándose — desde mediados del sigloxiII — de acuerdo con lateoría métrica (sílaba/tiempo/cuantidad/número: longa, breve), precisando cada vez más la longitud o brevedad, es decir, multiplicando o dividiendo matemáticamente el valor (duración) de las figuras. Ambos tipos de medida, no obstante, siguieron conviviendo - la métrica en la polifonía y la rítmica en el canto llano y monodia civil_, e influyéndose mutuamente.

Dentro del desarrollo delritmo en la música europea, podría hablarse de un triple proceso de "fusión" o "transformación" de ambos conceptos de medida: 1) "cuantidad en acento" (poesía: Edad Media); 2) "acento en cuantidad" (música: Ars Antiqua-Renacimiento); y 3) "cuantidad en acento" (música del Barroco).

\section{0.- ANTIGÜEDAD TARdía: ESCRITORES CRISTIANOS}

La música cristiana (latina) nació íntimamente unida al lenguaje de los te xtos bíblicos del Antiguo y Nuevo Testamento "en prosa", usados en el culto; aunque hay que esperar al siglo IX, para conocer los primeros códices con la música de dichos te xtos. Estos textos latinos son traducciones del arameo y del griego, realizadas en la época patrística (Vetus latina, Vulgata, siglos III-IV), en que el culto cristiano se latinizó. La Vulgata, realizada por San Jerónimo a finales del siglo r, terminó imponiéndose en la

9 Todavía, por los años cuarenta del siglo xx, seguíamos aprendiendo los fundamentos de la gramática latina en $\mathrm{v}$ ersos octosílabos: Es larga toda vocal / si consonantes siguieren / si muda y líquida fueren / no altera la cantidad...

10 -Wolf, Johannes: Handbuch der Notationskunde. I Theil. Wiesbaden, Breitkopf \& Härtel, 1975 [= Leipzig, Breitk opf \& Härtel, 1913], p. 200. [Traducción del autor]. 
cristiandad en el siglo VII. También se han transmitido te xtos en verso, como, entre otros, los himnos de San Ambrosio de Milán.

Se supone, que las melodías litúrgicas se regían por el acento del texto, recitado en voz alta. Existen numerosos códices literarios "premusicales", en los que, como he dicho anteriormente, aparecen acentos (signos prosódicos) para la correcta dicción de las palabras. Por otra parte, los salmos debían aprenderse de memoria, para lo cual serviría de apoyo el paralelismo (semejanza) de los miembros de cada versículo y el acento idiomático. Si bien la atención de los Santos $\mathrm{P}$ adres se centró principalmente en el ethos de la música, no obstante, han llegado hasta nosotros numerosas recomendaciones suyas sobre el modo de cantar estos textos en prosa ${ }^{11}$. Especialmente San Agustín somete a la razón, es decir , al número, las normas o principios de la prosodia latina, que dictaban la recitación o pronunciación de textos en prosa y en verso.

El primer escritor cristiano, que se ocupa amplia y profundamente del "ritmo musical", es SAN Agustín (*354; †430) en su tratado De musica, libri sex ${ }^{12}$. En cuanto al contenido (musical y teológico) y forma (diálogo, didáctico), revela, frente a los gramáticos y retóricos de su época ${ }^{13}$, la intención racionalconstructiva de fundamentar el ritmo musical en las ciencias matemáticas (número). Su importancia e influencia en posteriores escritores de música, desde Casiodoro hasta el siglo XVI (Francisci Salinae [...] De Musica. Libri septem . Salmanticae, Mathias Gastius, 1577), está fuera de duda ${ }^{14}$. No obstante, su teoría musical, tan rica en matices sobre el ritmo (medida suelta) y el metro (medida atada), no fue debidamente desarrollada en la teoría y práctica musical del canto gre goriano y polifonía medie val, ni justamente valorada por la investigación musical del siglo XIX (Forkel, Westphal, Ambros) ${ }^{15}$. San Agustín, más alla de la teoría de Aristógenes o Arístides Quintiliano, establece como principio, que el fundamento del ritmo, como movimiento ordenado, no es la sílaba (larga, breve) o el tiempo (tempus) primo (chronos protos: Arístides Quintiliano), sino el número.

11 -Pothier, Dom Joseph: op. cit., pp. 65-80 y 135 ss.

12 Publicado en: Obras Completas de San Agustín, xxxix, Biblioteca de Autores Cristianos (499). Madrid, BAC, 1988, pp. 70-361. Citado en adelante del modo siguiente: "BAC 499, p..".

13 San Agustín es contemporáneo de San Jerónimo (*348; †420, discípulo de Elio Donato s. IV), cuya Biblia Vulgata, se impuso frente a la Vetus Latina. Los modelos de San Jerónimo fueron Cicerón, en cuanto al estilo, y Orígenes, respecto a la teología. San Agustín, sin embargo, depende más de Varro (*116; †27 a.C.), cuya obra De lingua latina es de gran importancia para el conocimiento del antiguo latín y de las teorías lingüísticas helenistas. Entre los libros de enseñanza, que la edad med ia tomó de la antigüedad latina, están los de gramática: de Donato (350c), Ars minor y Ars maior; y Prisciano (siglo vI): Institutiones grammaticae, que cuenta como la obra más completa sobre la lengua latinacf $r$.: artículos "Augustinus", "Hieronymus", "Donatus" y "Priscianus", en Tusculum Lexikon. Munich, Heimeran Verlag, 1963). Al parecer, en tiempos de San Agustín, se mezclaban, en la medida, los términos aritméticos y geométricos: aritmética/números [ I, II, III, etc.]; geometría/cuantidades o dimensiones [punto, línea, longitud, superficie: ángulo, triángulo, cuadrángulo, etc.]; BAC 499, p. 277: "no e xiste tiempo sin alguna longitud" (movimiento: velociter, tarde) [movimiento lento = tiempo largo; movimiento rápido $=$ tiempo breve $]$ ). El tiempo $=$ semipié [sílaba] puede ser largo o breve. Hay semipiés largos, que no pueden ser sustituidos por dos tiempos bre ves, otros, en cambio, pueden serlo. Puede darse, por lo tanto, equi valencia de pies: por ejemplo, el dáctilo (3 tiempos: lar ga-breve-breve) puede ser sustituido por un espondeo (dos tiempos: lar ga-larga), el troqueo (dos tiempos: lar ga-breve) puede ser sustituido por un coreo (breve-breve-breve); el coreo (breve-breve-breve) y el yambo (breve-larga) son también intercambiables (breve-breve-breve/longabreve = longa-breve/breve-breve-breve; etc.).

14 Cfr.: -Fernández de la Cuesta, Ismael, trad. y ed.: Francisco Salinas. Siete libros sobre la música. Madrid, Colección Opera Omnia, Rodrigo de Zayas, 1983, pp. 483-495, 507 ss., 654-656.

15 Cfr.: -Hüschen, Heinrich: "Augustinus", en Die Musik in Geschichte und Gegenwart. I. Kassel, Bärenreiter, 1949-1951, columna 851 . 
Cuando escribió este tratado de música,Agustín era un joven profesor de retórica en Milán, admirador de San Ambrosio y de los clásicos latinos, especialmente M. T. Cicerón, Horacio Flaco (BAC 499, p. 282) y P. Virgilio M. (BAC 499, p. 274), cuyas doctrinas y v ersos cita constantemente. Fue uno de los primeros teóricos latino-cristianos, que, como retórico, se propuso cimentar el ritmo en las ciencias matemáticas como antes hiciera Arístides Quintiliano o, después, Marciano Capella, Casiodoro, Isidoro de Sevilla, etc.

Términos o conceptos, tratados por San Agustín, como tempus (“diu, non diu”: prolong ado, no prolongado), motus ("velociter, tarde": velozmente, lentamente), rhythmum, metrum, numerus, quantitas, acumen, accentus, pulsus, plausus, arsis, tesis, etc., son fundamentales para comprender la procedencia y desarrollo de la mensura y directio mensurae en la música medieval. Especialmente, con San Agustín, junto a Marciano Capella (siglo v), recibieron un gran impulso los dos antiguos conceptos de medida, que se generalizaron en la edad media, denominados:rítmico (número/medida continua, suelta) y métrico (metrum/medida discreta, atada).

San Agustín, en primer lug ar, define la música como "ciencia de modular bien" ( Scientia bene modulandi ${ }^{16}$; BAC 499, p. 73). Para San Agustín, modular bien es medir bien el tempus (espacio/movimiento, duración) de los sonidos (sílabas, notas). Modulación es una habilidad del mo vimiento. No podemos decir que una cosa se mue ve bien si no guarda medida. La modulación se funda en la razón (número) y en el sentido (oído). Mo vimento musical es el orden racionalizado de di versos pies métricos. La métrica, para él, no es materia de los gramáticos, sino de la música, que como scientia presupone el conocimiento de la aritmética (en la época de SanAgustín se mezclaban conceptos geométricos y aritméticos). Por eso, comienza su tratado (Liber I, BAC 499, pp. 95-108), explicando la medida (mensura) por medio del numerus, es decir, basándose en la aritmética - posteriormente algunos teóricos medievales de música llegarían a denominar arsmetrica - ${ }^{17}$, para pasar, después ( Libri II-V, BAC 499, pp. 119-283) a e xplicar los pies métricos y sus múltiples combinaciones (igual, dupla, sesquiáltera, epitritus, etc.), fundándose en proporciones numéricas.

En tiempos de San Agustín, algunos vocablos griegos, al ser traducidos al latín, habían cambiado o modificado su significado original. Esto lle garía a crear cierta confusión. El v ocablo griego árithmos término que no hay que confundir cora-rrhythmós (arítmico, desproporcionado)—, había sido traducido al latín como numerus. En griego, significaba cantidad, longitud, o también, duración,multitud, numeración, sistema numeral, aritmética. El v ocablo grie go rhythmós (movimiento re gulado por tiempos, medida, cadencia, regularidad, compás, armonía de un periodo, proporción regular, disposición simétrica, medida justa, figura, configuración, forma, carácter), fue traducido al latín también ponumerus. El vocablo griego métron (vara, regla, cantidad, medida, espacio, longitud, geometría), fue traducido al latín por metrum con el significado de "orden o medida fija basada en cuantidades silábicas o pies métricos". Por otra parte, en la cultura romana de los tiempos de San Agustín, predominaba la aritmética o ciencia de medir por

16 Marciano Capella (siglo IV/v), en su De nuptiis Mercuri et Phlilologiae, define la música de un modo semejante a San Agustín: "Musica est bene modulandi sollertia" (Música es la habilidad de modular bien), sólo cambia la palabra scientia [San Agustín: ciencia] por sollertia [Marciano Capella: habilidad]; y trata de la música "rítmica" y "metrica"; cfr.: -HüscHEN, Heinrich: "Capella, Martianus Minneus Felix", en Die Musik in Geschichte und Gegenwart. Vol. 2. Kassel, Bärenreiter, 1952, columna 803.

17 -Walter de Odington (CS I, 183 b). 
medio del número (a, b, c, etc., es decir, I, II, III, etc.), frente a la entonces decadente geometría o medida de espacios (longitudes) por medio de la cuantidad (punto, línea, triángulo, cuadrado, circunferencia). Esta mezcla de términos o conceptos geométricos y aritméticos creó aún más confusión. Por otra parte, vocablos diferentes como numerus o quantitas, rhythmus o metrum, muestran, en cuanto a su significado, como hemos visto, cierta semejanza, de ahí, que, en la teoría musical, se originara cierta congruencia entre ambos términos, ritmo o número/medida y metro o cuantidad/medida.

El ritmo puede ser entendido: $\boldsymbol{a})$ como el fluir natural y acompasado del tiempo y b) como el alma del metro, es decir, como lo que infunde vida ${ }^{18}$ o vivifica al metro. Metro, en cambio, es ritmo regulado y fijado (razonado) por la medida (número), es decir, un principio de articulación con el que se exterioriza el ritmo y se supone la forma. La primera definición indica, que el ritmo es una especie de fenómeno natural, que el hombre experimenta como medida y elabora racionalmente.

San Agustín parte de que: $\boldsymbol{a}$ ) todo ser humano distingue por el sentido, aunque no sepa razonarlo, la diferencia entre sílabas largas y breves; y b) lo que deleita en los sonidos son sus ritmos (mo vimientos). Ahora bien, el ritmo silábico se manifiesta de dos maneras: $\boldsymbol{a}$ ) en la cuantidad (larga o breve), o $\boldsymbol{b}$ ) en el acumen (acento), cuando las sílabas son de igual duración:

"Eo distat quod in diversis locis habent acumen".

("[Dos palabras iguales: el verbo pone y el adverbio pone] se distinguen, porque tienen el «acento» en lugares distintos"; BAC 499, p. 71).

De acuerdo con M. F. Quintiliano, San Agustín opina que cualquiera puede distinguir por el sentido del oído y el pulso si una sílaba es larga o breve:

"M[agister]: Ergo de omnib us huiusmodi sonis grammaticus judicabit; an per teipsum istos pulsus didicisti, sed nomen quod imponeres, a grammatico audieras? D[iscipulus]: ita est".

("Maestro: Por lo tanto, ¿es el gramático el que juzga, de este modo, sobre estos sonidos, o aprendiste estos pulsos [lar gos o bre ves] por tí mismo, aunque el nombre que les impones, lo hayas oído del gramático? Discípulo: Así es") ${ }^{19}$.

Según SanAgustín, medir los tiempos no es materia de lgramática, sino dela música. En el apartado "Quae de motibus et numeris sint rationes" (Lib. I; 7,13 - 13,28; BAC 499, pp. 95-118), racionaliza el ritmo por medio de proporciones numéricas y compara la sílaba con el tempus o medida del movimiento:

"Cum ergo inter se syllabae conferuntur, motus quidam inter se conferuntur, in quibus possint numeri quidam temporis mensura diuturnitatis inquiri".

Por tanto, ("cuando se comparan sílabas, se comparan mo vimientos, en los que pueden descubrirse números de cierto tiempo por la medida de su duración”).

18 -CApella, Martianus: De nuptiis Mercurii et Philologiae, Lib. IX: "numerum autem marem [533] esse, melos feminam nouerimus. et enim melos materies est, quae sine propria figura censetur, rhythmus autem opere quodam uirilis actus tam formam sonis quam uarios praestat effectus". (Edición, GS I).

19 SAn Agustín: BaC 499, 72. 
Para ello, define el tempus, no como sílaba, sino como número (tardanza proporcional en la pronunciación), partiendo de la relación entre espacio (largo/breve) y movimiento (lento/rápido). La diferencia entre las sílabas long a y bre ve se funda en la "duración” del mo vimiento. Del mismo modo que lo contrario a velociter (movimiento veloz) es tarde (movimiento lento), así también lo contrario a diu (tiempo largo, prolongado) es non diu (tiempo breve, corto). San Agustín pregunta "utrum quisquam possit et diu et v elociter currere" ("si alguien puede a la v ez correr un tiempo lar go [espacio, longitud] velozmente") (BAC 499, p. 95). La respuesta, en este caso, es afirmativa. En cambio, a la pregunta de "Quid, tarde et velociter?" (BAC 499, p. 96), "si es posible correr a la vez despacio y deprisa (tarde et velociter)", la respuesta es negativa. Así pues — concluye SanAgustín—, del mismo modo que lo contrario avelociter es tarde, lo contrario a diu (tiempo prolongado, larga duración) es non diu (tiempo breve, corta duración). Diu, por lo tanto, es tempus longum (tiempo largo) y, non diu, tempus breve (tiempo breve). Así que diu y non diu pueden ser mensurables (cuantificables) por medio del número. Un tiempo es la unidad o mínimo espacio, que ocupa la sílaba breve. De la breve pasamos a la longa, que dura dos tiempos.

Los gramáticos, sigue San Agustín (BAC 499, p. 119), diferenciaban entre sílabas largas y breves . Igual que sucede, cuando se comienza a contar desde el uno, así también, al pronunciar cualquier sílaba; cada una de ellas tiene su espacio (longitud: larga o breve) o movimiento (lento/longa o veloz/breve). Los antiguos, sigue San Agustín, no dijeron nada absurdo, cuando hablaron de la longa y la breve:

"Non absurde igitur hoc in tempore quasi minimum spatii, quo brevis obtinet syllaba, unum tempus veteres vocaverunt $[\ldots]$ a brevi enim ad longam progredimur $[. .$.$] Longa duplum spatium temporis habere$ deberet [...] Item [spatium] quod longa occupat recte duo tempora nominari”.

("Por lo tanto, los antiguos no denominaron absurdamentæiempo a ese quasi minimum de espacio, que recibe la sílaba breve [...], desde la breve progresamos a la longa [...]. La longa debe tener doble espacio de tiempo [...] Del mismo modo [el espacio] que ocupa la longa se ha de denominar rectamente «dos tiempos»" ${ }^{20}$.

Después de explicar la diferencia entre tiempo largo y breve, habla de diversas maneras de medida, es decir, de or ganizar las sílabas y los pies en el lenguaje. En primer lug ar (BAC 499, p. 160), distingue entre metrum (esquema cerrado, cuyo "orden" está configurado por una serie determinada, fija, de pies métricos, por ejemplo, un heámetro) y rhythmus (esquema abierto), cuyo “continuo fluir” está configurado por el predominio de un determinado pie métrico, por ejemplo, el yambo: bre ve-longa, que se repite continuamente. Ambos, metro y ritmo, están sometidos al número.

"Ergo quoniam oportet distingui etiam v ocabulis ea quae re ad se distincta sunt, scias illud superius genus copulationis, rhythmum a Graecis; hoc autem alterum, metrum v ocari: latine autem dici possent illud numerus, hoc mensio vel mensura".

("Por lo tanto, puesto que es necesario distinguir los vocablos cuando se refieren a cosas diferentes, debes saber que aquel género anterior de agrupación [serie continua] es denominada por los grigos ritmo, este otro, metro: en latín, aquél [ritmo, serie continua] se denomina número, este otro [metro] medida o mensura"21.

20 SAn Agustín: BAC 499, p. 125.

21 San Agustín: Bac 499, p. 161. 
[Recuerda a Cicerón: "Quicquid est enim quod sub aurium mensuram aliquam cadit, etiam si abest a versu —nam id quidem orationis est vitium — numerus vocatur, qui Graece rythmós dicitur".

(“Aquello que es de alguna especie medido por el oído, aunque no sea v erso — pues esto sería, verdaderamente, un vicio en el discurso — se denomina número, que en griego se dice ritmo")]22.

Una manera de ordenar las silabas y los pies es por medio del metrum y se basa en pies métricos de igual o diferente duración, que corren alternativamente, pero ordenados y articulados según un "esquema fijo" predeterminado, fundándose en el número y, ordenados de tal manera, que se sabe dónde termina la serie (por ejemplo, un he xámetro). Así pues, el metrum define (fija), por un lado, el pie métrico (por ejemplo, dáctilo: $2+1+1$; espondeo: $2+2$ )y, por otro, elesquema fijo de pies, denominado asimismometrum (hexámetro: 5 dáctilos +1 espondeo). El metro, dice San Agustín, discurre de tal manera (combinando pies diferentes), que puede saberse con certeza, cuándo comienza y acaba el "esquema fijo", es decir, cuándo hay que volver al principio o cuándo comienza el siguiente verso (BAC 499, p. 162).

Otra manera de organizar las sílabas y lospies, es por medio delrhythmus (medida suelta). SanAgustín somete también a la razón (aritmética) esta medida suelta, en tanto que se funda también en el número, es decir, en la distinción de longas (= dos tiempos) y breves (= un tiempo). Esta medida se apo ya en números continuos o pies "métricos" de la misma duración, que corren de un modo ininterrumpido y sin límite fijo, cuya organización y articulación se apoya en el oído (sentimiento). Es decir, por un lado, el ritmo se apoya en "golpes de pie sobre un escabel", que v an marcando, sin interrupción, tiempos bre ves, y, por otro, en el "gesto de la mano" (plausus, ictus), que va indicando el pie "métrico", que va repitiéndose, sin poder saber nunca, cuándo llega el final. Esto sucede, escribe San Agustín, cuando los músicos golpean con el pie los escabeles y címbalos, fundándose en "números fijos" (pies métricos de igual o semejante duración:tríbracos seguidos: breve-breve-breve, etc. o yambos seguidos: breve-longa, etc.), que se unen entre sí con agrado del oído, pero, no obstante, fluyen continuamente sin interrupción (tenore perpetuo), de modo que si "no oyeras las flautas, no podrías percibir hasta dónde se extiende dicha secuencia de pies, ni cuándo hay que volver de nuevo al principio", es decir, cuándo comienza el nue vo verso ("Ita ut si tibias non audias, nullo modo ibi notare possis quousque procurrat conexio pedum, et unde rursus ad caput redeatur"; BAC, 499, p. 160). Así pues, en este tipo de ritmo, además del constante "golpeo del pie" feriunt pede) en los scabella symphoniaci (pedestales de madera) y los cymbala, es necesario el plausus ("palmada", aplauso o gesto de la mano), que indica el arsis (elevatio) y la tesis (depositio), que da a conocer los dos latidos delpes (cédula rítmica binaria o ternaria), en que se basaba el orden rítmico, que, según San Agustín, adeo late patet ("latía hasta el punto de aparecer claro para todo el mundo"):

"Nam videtur, cum tale incertum evenit, plausu potius debere discerni quo pede curratur".

("Pues como se ve, cuando sucede tal incertidumbre, es mucho más necesario el plausus, para poder discernir en qué pie [métrico] se basa [el ritmo]"). (BAC 499, p. 170).

22 Wilkins, A. S.: M. Tulli Ciceronis Rhethorica. Tomus II. Oxford, Oxford Classical Text, 1982, p. 20, 66/67. 
La denominada medida rítmica, se gún San Agustín, podía ser e xpresada de di versas formas: 1) basándose en un número continuo (rhythmum), es decir, en una secuencia ininterrumpida de pies de "dos" o "cuatro" tiempos de igual duración y articulación como el pirriquio (dos semipiés breves), cuyos tiempos se articulan, uno al alzar (arsis, elevatio) y otro al dar (tesis, positio) o el prosceleumático (cuatro semipiés o tiempos breves), dos al alzar (arsis, elevatio) y dos al dar (tesis, positio); 2) basándose en un "número continuo" de pies de "tres tiempos" de igual duración, pero de desigual articulación, como el tríbraco (tres tiempos bre ves), que se articula poniendo los dos primeros al alzar ( arsis, elevatio) y el tercero al dar (tesis, positio) o al contrario; y 3) basándose en un "número continuo" de pies de desigual duración y articulación como el troqueo o coreo (dos semipiés, el primero largo o doble y el se gundo breve), que se articulan, poniendo el tiempo o semipié lago al dar (tesis, positio) y el breve al alzar (arsis, elevatio); o como el yambo (dos semipiés: el primero breve y segundo largo), también de "dos semipiés" de desigual duración y articulación, que, para diferenciarlo del troqueo o coreo, se articula poniendo el semipié breve al dar ( tesis, positio) y el lar go o doble al alzar ( arsis, elevatio). En todos estos casos, el plausus (movimiento de la mano) indicará el respectivo pie métrico, que rige la medida.

Para San Agustín, es de gran importancia, articular bien (acompasar) la medida de los pies métricos (tiempos/sílabas, palabras) y sus posibles combinaciones por medio del plausus, que consiste en el "alzar (levatio) y dar (positio) de la mano":

"Sed hoc nobis considerantibus, opus est haec duo nomina mandare memoriae, lationem et positionem. In plaudendo enim quia le vatur et ponitur manus, partem pedis sibi le vatio vindicat, partem positio. [...] Video primum p yrrhiquium tantum habere in le vatione quantum in positione. Spondeus quoque, dactylus, anapestus, proceleumaticus, coriamb us, diiamb us, dichorius, antipastus, dispondeus, eadem ratione dividuntur: nam tantumdem temporis in his ponit plausus, quamtum levat".

"Pero al reflexionar sobre este punto debemos recordar estos dos términos, alzar y dar . Al aplaudir, pues, como al alzar y bajar la mano, una parte del pie [métrico] e xige el alzar y la otra el dar . [...] Veo, en primer lugar, que en el pirriquio tiene la misma duración el alzar que el dar. En la misma proporción se mide también el espondeo [Long a / Long a], dáctilo [Long a / Breve-Breve], anapesto [BB / L], proceleumático [BB / BB], coriyambo [LB / BL], diyambo [BL / BL], dicoreo [LB / LB], antipasto [BL / LB], dispondeo [LL / LL], pues igual espacio de tiempo emplea en ellos la mano al levantar que al bajar”. (BAC 499, p. 146 ss.).

A continuación, San Agustín explica, cómo pueden combinarse (mezclarse) entre sí pies de la misma duración, por ejemplo, el ritmo tríbraco (tres breves) con el yámbico (breve-larga). En este caso, dentro del ritmo continuo o "igualdad de duración temporal", junto al golpeo con el pie, que señala el "ritmo continuo" (es decir, una breve en cada golpe), el plausus (dar y alzar de la mano) v a indicando o diferenciando el pie métrico (tríbraco o yambo), que rige esta medida rítmica:

"Video iudicium ad plausum illum esse revocandum, ut si unum tempus est in elevatione, duo in positione [...] aut contra, duae in levatione, una in positione; tribachus rhythmus esse dicatur".

("Veo que, debe ser restablecido juzg ar por el golpe de manos, para que un tiempo sea al elevar, dos al bajar [...] o al contrario dos al ele var, uno al bajar; que se dig a que eso es un ritmo tríbraco"). (BAC 499, p. 171). 
En resumen: cuando al oír una serie de "pies fijos", por ejemplo, dáctilos, al aparecer "un pie diferente" (un anapesto), se percibe como unfallo, es decir, cierta aversión del oído, dicha serie (continua) se denomina correctamente rhythmus (medida rítmica). Ahora bien, como este "continuo rodar de pies" no tiene un límite fijo, porque no existe "un pie o esquema fijo" que lo indique, ni tampoco existe medida para lo continuo, no se permitió llamarlo metrum (medida métrica). El metrum, sin embargo, comprende dos cosas; por un lado, corre sobre "pies fijos" y, por otro, se detiene en un "límite fijo". Así que, el metro se distingue del ritmo, no tanto por la "combinación re gular de pies" como por su "final claro". Por tal razón, aquí faltaría la cita original en latín "todo metro es ritmo, pero no todo ritmo es metro" ßAC 499, p. 161). Así pues, el ritmo existe en el verso, pero puede aparecer también en laprosa; el metrum, en cambio, sólo puede existir en el verso.

Una de las obras de San Agustín, redactada hacia el año 394, es el Psalmus contra partem Donati, que ha lle gado a ser considerado como el prototipo del denominado verso rítmico medieval. Consta de verso y responsión popular — a la manera de los himnos - dímetros yámbicos de San Ambrosio de Milán-, sólo que San Agustín basa el ritmo del verso en el acento y número de sílabas del texto.

El tratado de M. S. B oecio $(* 480 ; \uparrow 524)$, De institutione musicae, ejerció gran influencia durante la edad media y renacimiento. Este tratado se funda en las teorías trasmitidas de Pitágoras, Nicómaco (siglo II d.C.) o Ptolomeo (siglo II d.C). Para Boecio, como para San Agustín, el numerus es esencial en la música. Cita a Albino (siglo Iv), que, en su tratado de música, ho y desaparecido, trataba de la medida continua del lenguaje, gobernada por el ímpetu del lenguaje, frente a la medida discreta, que define los intervalos, en los que se basa la música armónica. Respecto al ritmo del lenguaje, Boecio habla de tres clases de medida: a) continua, que no se apoya en sonidos largos o breves, sino en el ímpetu (acento) del lenguaje; b) discreta, que se apo ya en metros definidos y c) media, que se sitúa entre la prosa (medida continua) y el v erso (medida discreta). Esta medida media se asemeja a lo que San Agustín denomina ritmo:

"OMnis uox aut [SUNEChes] [sineces supra lin.] est quae continua. aut [DRSTEMATIKE] [diastematice supra lin.]. quae dicitur cum interuallo suspensa Et continua quidem est: quia loquentes uel ipsam orationem legentes uerba percurrimus. Festinat enim tunc uox non haerere in acutis et grauib us sonis. sed quam uelocissime uerba percurrere. e xpediendisque sensib us: e xprimendisque sermonib us continuae uocis impetus operatur. [DiAsteMATIKE] autem est [ea add. supra lin.] quam canendo suspendimus. in quam non potius sermonibus sed modulis inseruimus. estque uox ipsa tardior et per modulandas uarietates quoddam faciens interuallum: non taciturnitatis sed suspensae [suspendida] ac tardae potius cantilenae. His ut Albinus autumat additur tertia dif ferentia. quae medias uoces possit includere. sed [f.15v] cum scilicet heroum poemata le gimus. neque continuo cursu ut prosam neque suspenso se gniorique modo uocis ut canticum".

("Toda voz puede ser continua o separada por espacios [discreta]. Es continua, cuando, al hablar o leer un discurso, decimos se guidas las palabras. Por lo tanto, cuando [alguien] acelera la $\mathrm{v}$ oz, no se detiene en los sonidos agudos y gra ves [largos y breves], sino que recorre velozmente las palabras y, dejando libre los sentidos [sentimientos] y e xpresando los discursos, se deja lle var por el ímpetu de la voz continua. [Voz discreta o separada por espacios: intervallum], sin embargo, es cuando nos 
detenemos [alargamos] al cantar; aquella en la que no nos servimos más de la con versación, sino de medidas [ modulos]; y esta misma es más tarda [lenta], pues hace un determinado interv alo para medir las variedades (varietates), no por medio del silencio, sino alar gando y deteniendo mucho más la cantilena. A estas [v oz continua y v oz separada por espacios], como opina Albinus [siglo II], se añade una tercera diferencia, que pueda incluir las voces medias, pues cuando, a saber, leemos poemas heroicos, no lo hacemos de un modo se guido [continuo] como en la prosa, ni con medida prolong ada y soñolienta de la v oz como en el cántico"). (-B oEthius, Anicius Manilius Severinus: De institutione musica. Liber I. Cambridge, Trinity College, R.15.22 (944), ff. 14r.-15v.; cfr.: -Boetius: De musica. Thesaurus Musicarum Latinarum).

F. M. Aurelio Casiodoro (*490; †585) Caput v, Libri Cassiodori De Musica (gS I, 15), discípulo de Boecio $(* 480 ; \uparrow 524)$ ejerció gran influencia durante la edad media. En el monasterio Vivarium, que fundó al sur de Italia, reunió una gran biblioteca de autores clásicos.Tradujo los salmos bíblicos en versos latinos, dotándoles de signos de acentuación para facilitar su recitación a los monjes.

Al final del capítulo v, después de citar tratadistas grie gos como Euclides (siglo III a.C.), Ptolomeo (siglo II), Nicómaco de Gerasa(siglo II) oAlypio (siglo III-IV), y latinos comoApuleyo Madaurense (fl. siglo II) y Muciano ( $f$ l. siglo vi), habla expresamente de SanAgustín, que trató sobre el ritmo (rhythmicos sonos) y la medida ( harmoniam modulabilem in longis syllabis atque brevibus ); como también del gramático latino Censorino ( $f$ l. Roma, siglo III), que trató sutilmente el acento (de accentibus), "tan necesario en la lengua latina, que debe ser incluido en la disciplina musical" ("Censorinus quoque de accentib us voci nostrae adnecessariis subtiliter disputavit, pertinere dicens ad Musicam disciplinam”; GS I, 19b):

"Scripsit etiam et Pater Augustinus de Musica sex libros, in quibus humanam vocem, rhythmicos sonos et harmoniam modulabilem in longis syllabis atque bre ves naturaliter habere monstra vit. Censorinus quoque de accentib us v oci nostrae adnecessariis subtiliter disputa vit, pertinere dicens ad Musicam disciplinam; quem vobis inter caeteros transcriptum reliquia”.

(“El padre Agustín también escribió seis libros de música, en los que demostró que la øz humana tenía sonidos rítmicos y armonía mensurable naturalmente en long as y breves. Censorino disputó sutilmente sobre los acentos necesarios para nuestra $\mathrm{v}$ oz, diciendo que pertenecían a la disciplina musical, lo que, entre otros, dejó escrito para vosotros"). (GS I, 19 b).

Casiodoro define la música de dos maneras: la primera ( scientia bene modulandi) es copia literal de San Agustín. Interesa aquí, la estrecha relación del ritmo musical con el pulso de las v enas y las emociones interiores, ya citados por M. F. Quintiliano o Nicómaco (sentimiento):

"Quidquid enim loquimur, vel instrinsecus v enarum pulsib us commo vemur, per musicos rh ythmos harmoniae virtutibus probatur esse sociatum. Musica quippe est scientia bene modulandi: quodsi nos bona conversatione tractemus, tali disciplinae probamur semper esse sociati [...] Caelum quoque et terra, vel omnia, quae in eis superna dispensatione peraguntur, non fiunt sine musica disciplina: cum Pytagoras hunc mundum per Musicam conditum, et gubernari posse testetur".

("Pues lo que hablamos, o cuando nos emocionamos intrínsecamente por el pulso de las v enas, está probado que va asociado a las fuerzas de la armonía por medio de los rítmos musicales. Música, por lo 
tanto, es la ciencia de modular bien : pues si nos tratamos con b uenas maneras, siempre demostramos estar asociados a tal disciplina [...] El cielo y también la tierra, o todo, lo que actúa en ellos por la providencia suprema, no sucede sin la disciplina musical: ya dijo Pitágoras que este mundo fue creado y es gobernado por la música"). (GS I, 16 a).

En la siguiente definición resuena el pensamiento de San Agustín, al fundamentar los principios de la música en el número:

"Nunc de musicae partib us, sicut est a Maiorib us traditum, dif feramus: Musica est disciplina v el scientia, quae de numeris loquitur, qui ad aliquid sunt his, qui inveniuntur in sonis; ut duplum, triplum, quatruplum, et his similia, quae dicuntur ad aliquid".

("Ahora distingamos las partes de la música, como nos han trasmitido los antiguos: Musica es la disciplina que trata de los números que están referidos a algo, que encontramos en los sonidos: como doble, triple, cuádruple, y otros semejantes a estos, que se dicen referidos a algo"). (GS I, 16 a).

Divide la música en tres partes: harmonica, que establece la diferencia de altura de los sonidos; rhitmica que se funda en la cohesión de las palabras con los sonidos; ymetrica, que se funda en la medida de los metros.

"Musicae partes sunt tres; nam vel est illa Harmonica, vel Rhythmica, vel Metrica. Harmonica scientia est musica, quae discernit in sonis acutum et grae. Rhythmica est, quae requirit in concursione erborum, utrum bene sonus, an male cohaereat. Metrica est, quae mensuras diversorum metrorum probabili ratione cognoscit; ut verbis gratia, heroicum, iambicum, elegiacum, et caetera".

("La música consta de tres partesAmónica, Rítmica o Métrica. Lamúsica armónica, es la que distingue entre sonidos agudo y gra ve. Rítmica, la que requiere la colaboración de las palabras, si el sonido se adecua bien o mal. Métrica es la que conoce con razón probable las medidas de los di versos metros: como, gracias a las palabras [se distingue], el heróico, el yámbico, el elegíaco, et caetera"). (GS I, 16 a).

Esta división tripartita aparecerá frecuentemente, como veremos, en numerosos teóricos medievales. Según esta definición, en la música rítmica, la relación músicaltexto es determinante, para que los sonidos (notas) y las palabras sean coherentes entre sí o exista "cierto orden" entre ellos.

San Isidoro de Sevilla ${ }^{23}$ (*560c; $\left.\uparrow 636\right)$, DE Musica ${ }^{24}$ (Etimologías, i) se ocupa de la cuantidad silábica (métrica) y del acento silábico en lagramática (BAC 433, pp. 299-308). El estudio de la música se incluye dentro de las matemáticas (BAC 433, pp. 443-454), después de la aritmética y geometría.

Si SanAgustín había intentado captar medir y definir el tempus (movimiento) por medio delnúmero, San Isidoro relaciona el tempus (traducción latina del griego chrónos) con el tiempo físico o movimiento de los astros:

23 Sententiae Isidori Episcopi ad Braulionem Episcopum de musica (GS I, 20 a).

24 -San Isidoro de Sevilla: "De Musica”, en Etimologías, I. Madrid, Bac 433, 1982, pp. 443-454. 
"Tempora autem momentis, horis, dieb us, mensib us, annis, lustris, saeculis, aetatib us di viduntur. Momentum est minimum atque angustissimum tempus, a motu siderum dictum. Est enim e xtremitas horae in brevibus intervallis, cum aliquid sibi cedit, atque succedit".

("Los tiempos se dividen en momentos, horas, días, meses, lustros, siglos, edades. Momento es un tiempo mínimo y reducidísimo, denominado así por el movimiento de los astros. Es el límite de las horas en breves intervalos, cuando algo cede y sigue"). (Ethymologiae, De legibus et temporibus. BAC 433, p. 536).

Más adelante, entiende el tiempo como acción humana: tiempo es lo que sucede dentro del tiempo (chronos). El tiempo, en sí mismo, no puede ser entendido, sólo es comprensible, si lo relacionamos con una acción:

"Intempestum est medium et inactuosum noctis tempus, quando agi nihil potest et omnia sopore quieta sunt. Nam tempus per se non intelligitur, nisi per actus humanos. Medium autem noctis actum caret".

("Intempestuoso e inactivo es el tiempo de la media noche, cuando no se puede actuar y todo está quieto por el sopor. Pues el tiempo no se entiende por sí mismo, sino por los hechos humanos. La media noche, sin embargo, carece de hechos"). (Ethymologiae, De legibus et temporibus. BAC 433, p. 542).

En sentido semejante, hablará del tiempo Juan de Grocheo (finales del siglo XIII), como veremos más adelante.

Tanto en las Etimologías, como en Sententiae Isidori Episcopi ad Braulionem Episcopum de musica (GS I, 20 a), San Isidoro define y divide la música de un modo semejante a Agustín y Casiodoro: "Musica est peritia modulationis sono cantuque consistens" 25 ("Música es la pericia de modular [medir], que consta de sonido y canto"), y repite la conocida división tripartita (A. Quintiliano, Casiodoro) de música: armónica, métrica y rítmica ${ }^{26}$ :

"Musica est harmonica, rh ythmica vel metrica ${ }^{27}[\ldots]$ Musica harmonica est quae discernit in sonis acutum et gravem [id est, modulatio vocis, pertinet ad comoedos et tragoedos, vel choros, vel ad omnes, qui propria voce canunt]. Rhythmica est quae incursionem terborum, utrum bene sonus an male cohaereat. Metrica est, quae mensuram diversorum metrorum probabili ratione cognoscit, ut verbi gratia heroicum, iambicon vel elegiacon, et caetera".

("La música es armónica, rítmica o métrica [...] Música armónica es la que distingue entre sonidos agudos y graves (es decir, modulación de la voz, pertenece a los comediantes y trágicos, o a los coros, o a todos los que cantan con la propia v oz). Rítmica la que requiere la colaboración de las palabras. Si se adecuan bien o mal entre si. Métrica es la que conoce con razón probable la medida de losudirsos metros, como por ejemplo, el heróico, el yámbico o elegíaco, et caetera"). (GS I, 21 a; BAC 433, Ethymologiae, op. cit., p. 445).

25 La definición isidoriana está calcada de la que nos da Censorino (siglo III) en De die natali, 10, 3, que a la vez, depende de M. T. Varro (*81; †27 a.C.); cfr.: -SAn Isidoro De Sevilla: "De Musica”, en Etimologías, i. Madrid, Bac 433, 1982, p. 442, nota 29.

26 Cfr. también: -San Isidoro de Sevilla: "De Musica”, en Etimologías, i. Madrid, bac 433, 1982, p. 445.

27 -San Isidoro de Sevilla: "De Musica", en Etimologías, i. Madrid, Bac 433, 1982, p. 445, nota 34. Marciano Capella (siglo III/IV) en su definición de música dice: "Quae ad melos pertinet, harmonica diciturquae ad numeros, rythmica; quae ad rerba metrica" ("La que afecta a la melodía se denomina armónica, la que a los números, rítmica; la que a las palabras, métrica"). 
Musica harmonica es el canto, que se compone de sonidos agudos y gra ves. Musica rhytmica es la que se basa en la coherencia entre las palabras y sonidos (prosa) ymusica metrica, la que se somete a una medida fija (verso).

Aparece también, al pie de la letra, la idea de Casiodoro, anteriormente e xpuesta, de que, cuando hablamos o sentimos emociones, todo está relacionado con los ritmos, debido a las fuerzas de la armonía musical:

"Sed et quidquid loquimur, vel intrinsecus v enarum impulsu (pulsib us) commo vemur, per musicos rhythmos harmoniae virtutibus esse sociatum".

("Pero lo que hablamos, o cuando nos conmovemos interiormente por el impulso (pulsos) de las renas, está unido a las fuerzas de la armonía por medio del ritmo [número] musical”). (GS I, 20 b - 21 a).

En las Etimologías, añade, que la música mue ve los afectos del alma: Musica movet affectus (BAC 433, p. 444).

A lo expuesto en las Etimologías, San Isidoro añade, en este breve tratado, dirigido a San Braulio de Zaragoza, otros aspectos del sonido:

"Tonus est acuta enuntiatio vocis. Est enim harmoniae differentia et quantitas, quae in vocis accentu vel tenore consistit [...] Cantus est inflexio vocis. Nam sonus directus est, praecedit autem sonus cantum".

("Tono es la pronunciación aguda de la v oz [sonido]. Es, en efecto, diferencia de armonía y cantidad, que consiste en el acento de la $\mathrm{\nabla z}$ o en el tenor [moimiento seguido, recto] [...] Canto son las inflexiones que hace la voz al cantar. El sonido es directo, el sonido precede al canto"). (GS I, 21 b).

También habla de los sistemas de medida, definidos por SanAgustín: el relacionado con larhythmica, "regido per incursionem verborum" [impulso de las palabras], es decir , regido por el ritmo del idioma (numerus = accento silábico) yel relacionado con lametrica, basado en lamensuram diversorum metrorum (medida de los diversos metros), es decir, regulado por el metro (numerus = cuantidad silábica).

Sobre el acento (agudo, gra ve, circunflejo), dice, que fue in ventado para distinguir (articular) las palabras o para pronunciarlas bien:

"Accentus autem reperti sunt vel propter distinctionem [...]; vel propter pronuntiationem".

("El acento se inventó para la distinción [diferenciación] [...] o para la pronunciación”).Ęthymologiae, op. cit., p. 306).

La importancia de la música es resumida por Isidoro en el conocido apote gma: "Sine musica nulla disciplina potest esse perfecta". ("Sin la música ninguna disciplina puede ser perfecta"). ( GS I; 20 b). 


\section{1.- Alta EDAD MEDIA: DESDE EL "RENACIMIENTo CAROLINGIO"}

Ambos sistemas de medidamétrica y rítmica aparecen en SCHoLIA ENCHIRIADIS (hacia el siglo viII; GS I, 182 b y 183 a) confusamente mezcladas, referidas al canto llano. Cuando habla de numerose ${ }^{28}$ canere, debería, por el conte xto, traducirse más bien en sentido rítmico (acento silábico o medida continua o suelta, según Boecio), que métrico (cuantidad silábica) ${ }^{29}$. El autor habla de un tipo de canto silábico, que agrupa proporcionalmente (numerosamente) las palabras, rigiéndose por el acento idiomático, como fuerza centrípeta, y descansa en la sílaba final de cada miembro: la cantilena diríjase con palmadas (plausus) como si fuera con pies métricos:

" $\mathrm{D}$ [iscipulus] Quid est numerose canere? M[agister]. Ut attendatur, ubi productioribus, ubi brevioribus morulis utendum sit: Quatenus uti quae syllabae breves, quae sunt longae, attenditur; itaque soni producti quique correcti esse debeant, ut ea, quae diu, ad ea, que non diu, le gitime concurrant, et veluti metricis pedibus cantilena plaudatur. Age canamus exercitii usu; plaudam pedes ego in praecinendo, tu sequendo imitabere: Ego sum via v eritas et vita. / Alleluia. / Alleluia. /. Solae in trib us membris ultimae long ae, reliquae breves sunt. Sic itaque numerose est canere, longis bre vibusque sonis ratas morulas metiri [...] ut possit melum ea finiri mora, qua cepit”.

("Discípulo: ¿Qué es cantar numerosamente? Maestro: prestar atención a dónde hay que usar tardanzas [morulae] más prolong adas y, dónde, más bre ves: cuidar dónde usar las sílabas bre ves y las long as; y cuándo se usan sílabas bre ves o longas, para que concurran le gítimamente los que son prolong ados y los que no lo son, y la cantilena se rija con las palmadas (plausus) como si fuera con pies métricos. Cantemos, hag amos un ejercicio, yo, al cantar, señalaré con palmadas los pies [métricos], tu sígueme imitándome: Ego sum via veritas et vi ta / Allelui a / Allelui $\boldsymbol{a}^{30}$. En los tres miembros una sola long a al final, las otras son breves. Así, este modo, se denominacantar numerosamente; medir con las «tardanzas» exactas los sonidos largos y breves [...] para que la melodía pueda finalizar con la «tardanza» [nota larga] que comenzó”). (GS I, 182 b y 183 a ).

Bernonis Augiensis [Berno de Reichenau (*978c; †1048), abad del célebre monasterio de Reichenau, situado en una isla dentro del Lago de Costanza (1008-1048), compilador de un tonario y reformador del canto gregoriano, que or ganizó en ocho “tonos"], Prologus in tonarium (GS II, p. 77 a). Ho y se piensa, que esta obra se remonta al siglo IX, es decir, a la época de Aureliano de Reomé, Hucbaldo o Re gino de

28 San Agustín, al tratar del "Pes anfibrachus [o proporción tripla: breve / longa-breve]", dice lo siguiente: (Cur iste pes ad seriem numerosam vocum non admitatur?). “¿Por qué este pie no se admite en la serie numerosa [rítmica]?”. (BAC 499, p. 148).

29 Cicerón explica detenidamente en el Orator, citado en la primera parte de este trabajo, el concepto de "cantar con medida" ( numerose), acompasada o rhythmica. "Si numerosum est id in omnib us sonis atque v ocibus, quod habet quasdam impresiones et quod metiri possumus interv allis aequalibus, recte"; cfr. "Numerose" y "Numerosus" en Georges LateinischDeutsches Handwörterbuch. 2 Band I-Z. Basel, Nachdruck Darmstadt, 1967, p. 1218. Estos términos son usados frecuentemente por Cicerón, Horacio, Quintiliano, etc. y, como veremos, por numerosos teóricos medie vales para referirse a una medida basada en el ritmo natural del idioma, que deja percibir ritmos como el yambo, coreo, troqueo, peón, etc.). Cfr. también: -PotHIER, Dom Joseph : Les mélodies grégoriennes. Tournay, Impr. liturgique de Saint Jean L'évangéliste, Desclée Lefebvre, 1880 (París, Stock Musique, 1980, p. 179 ss.). Dom J. Pothiers analiza aquí la antífona gre goriana "Ego sum via", citada en este te xto del Scholia Enchiriadis.

30 Ego sum via “3+2" / veritas et vita "4+2", en total, un endecasílabo, dividido en dos partes: 5+6 sílabas. 
Prüm ${ }^{31}$. El autor de este prólogo mezcla los términos "métrico" (debitam quantitatem: medida/cuantidad) y "rítmico" (numerositatem: medida/acento), cuando advierte, que, al cantar, deben evitarse, entre otros, los vicios de correr o detenerse caprichosamente en las notas, pues hay que obserar "la tardanza adecuada al ritmo (número/acento)" (aptae numerositatis moram). Habla claramente del ritmo del acento e incluso pone ejemplos. Es importante la observ ación que hace: "non enim grammatica, sed musica hominem consistere percepimus", que podría muy bien traducirse como que "el hombre no es sólo razón, sino también sentimiento", es decir, que "la medida no puede reducirse a una pura fórmula matemática, ya que, junto a la razón (cuantidad, metro), actúa también el sentimiento (ritmo del pulso humano: que está dentro de ti), que es más difícil de formular con tanta precisión”. En este escrito, resuena la doctrina de San Agustín. En el siguiente párrafo habla de larazón musical, a la que pertenece larazonable dimensión y numerosidad (numerositas), frente a la razón de la cuantidad:

"Neque audiendi sunt, qui dicunt, sine ratione omnino consistere, quod in cantu aptae numerositatis moram nunc velociorem, nunc vero faciamus productiorem: si grammaticus quilibet te reprehendit, cum in versu eo loci syllabam corripias, ubi producere debeas, nulla alia causa naturaliter istente, cur magis eam producere debeas, nisi quia antiquorum ita sanxit auctoritas; cur non magis musicae ratio, ad quam ipsa rationabilis vocum dimensio et numerositas pertinet, succenseat quodammodo, si non pro qualitate locorum observes debitam quantitatem morarum? Si aliquado of fendere te potuit male prolatum [mal proferido, medido], quod est extra te, quantum magis quod est intra te? non enim grammatica, sed musica hominem consistere percepimus: quod, ut viri eruditissimi verbis utar, quisquis in sese ipsum descendit, intelligit: Idcirco ut in metro certa pedum dimensione contexitur versus, ita apta et concordabili brevium longorum sonorum copulatione componitur cantus: et elut in hexametro versu si legitime currit, ipso sono animus delectatur. [...] sic in cantilena e x vetere auctoritate apta et modesta modulationum coaptatione coniuncta, tota animae corporisque compago [unión] delectatur: sicut econtrario ab audiendi voluptate se suspendit, siquid in ea depravatum sentit".

("No hay que hacer caso a los que, sin razón alguna, dicen que en el canto hay que hacer la tardanza, adecuada a la medida rítmica, más v eloz o más lenta: si algún gramático te reprocha si acortas la sílaba en el verso, cuando debes alargarla, sin existir causa alguna natural, por qué debes alargarla, sino porque así lo sancionó la autoridad de los antiguos porque no es mayor la razón de la música, a la que pertenece esa dimensión razonable y rítmica (numerositas); ¿tiene alguien en cuenta de algún modo, si, debido a la cualidad de los lugares, no observas la debida cuantidad de las tardanzas (duraciones)? ¿Dónde empieza ese interrogante que se acaba de cerrar? Si alguna \&z te pudo molestar lo mal proferido (emitido, medido), que está fuera de ti, ¿cuánto más lo que está dentro de ti? La consistencia del ser humano no la percibimos por la gramática, sino por la música: lo que, usando palabras de gente muy erudita, significa que quien profundiza dentro de sí mismo, entiende. Así como el metro se funda en la medida cierta de los pies, así el canto se compone de la unión apta y concordante de sonidos lar gos y breves: y como en el v erso exámetro, si discurre le gítimamente, con su sonido deleita el ánimo [...], así con la cantilena, adecuada a la apta y modesta medida, según la autoridad de los antiguos, se deleita el cuerpo unido al alma: como, por el contrario, se suspende el placer de oír, cuando siente en ella algo malsonante"). (GS II, 77 b).

31 Cfr.: Brockhaus Riemann, Musik Lexikon. Vol. A-D. Munich, Piper Verlag, 1989, p. 137 a. 
Alcuino (*735c; †804): "Flacci Alcuini seu Albini Musica [saec. viII]" (GS I, 26) define la música de dos maneras: a) musica est divisio sonorum, et vocum varietas, et modulatio canendx" "Música es división de sonidos [armonía], v ariedad de voces [melodía] y medida al cantar”); y algo después: b) musica est disciplina, quae de numeris loquitur, qui inveniuntur in sonis ("Música es la disciplina que trata de los números, que se encuentran en los sonidos") (GS I, 26 a).

Compara el tono, sonido definido o mínimo intervalo musical (fundamento de la melodía), con la sílaba, mínima parte de la gramática (fundamento del discurso):

"Tonus est minima pars musicae re gulae. Tamen sicut minima pars Grammaticae littera, sic minima pars Arithmeticae unitas: et quomodo litteris oratio, unitatibus acervus multiplicatus numerorum surgit et erigitur, eo modo sonorum tonorumque linea omnis cantilena modulatur".

("El tono [intervalo] es la mínima parte de la rela musical. Como la mínima parte de la gramática es la letra, así la mínima parte de la aritmética es la unidad [numerus]: y lo que es un discurso con relación a las letras, que como un acerv o multiplicado de números sur ge y se construye con unidades, del mismo modo, toda cantilena o línea de tonos y sonidos es modulada [medida]"). ( GS I, 26 a).

J. Wolf cita los siguientes versos de Alcuino dirigidos a Carlomagno, en los que parece referirse al acento como sonido musical y también como elemento necesario para articular el canto:

"Hos regat et doceat, certis ne accentibus errent [...] Utque sonos dulces decantent voce sonora / Quot pedibus, numeris, rhythmo stat musica, discant [pueri]".

("Dirija y enseñe [a los niños], para que no se equi voquen en los v erdaderos acentos [...] P ara que canten sonidos dulces con v oz sonora / Y aprendan, cuántos pies, números y ritmo hay en la música"). (Johannes W olf: Handbuch der Notationskunde. I. Wiesbaden, Breitk opf \& Härtel, 1975 [= Leipzig, 1913], p. 108).

Remigi Altisiodorensis Musica (saec. ix) (GS I, 63). [Remigio de Auxerre (*841; †908), gramático, matemático y comentarista, discípulo de Enrique deAuxerre. Maestro en Auxerre, Reims (donde restauró las escuelas con Hucbaldo de SanAmando) y París. Glosó la obra de autores como SanAgustín, Boecio o Marciano Capella]. Estas glosas del tratado de Marciano Capella De nuptiis Mercuri... siglo IV) se ocupan del ritmo musical, siguiendo la teoría de Aristógenes: "Est quoque distantia inter rh ythmum metrumque non parva" ("No es pequeña la distancia entre ritmo y metro").

"Rhythmus visu, auditu, tactuque percipitur: in corporis motum: in sonorum modulandique rationem: atque in $v$ erba, quae apta ratio modis collig arit, quae cuncta socia $f$ aciunt cantilenam. Di viditur sane numerus in oratione (per syllabas); in modulatione per arsim et thesim".

("El ritmo se percibe por la vista, el oído y el tacto: en el mo vimiento del cuerpo: en la lógica de los sonidos y medida: $\mathrm{y}$ en las palabras, que la apta razón vincula a las medidas [modus = metrum]: todo esto asociado constituye la cantilena. El número se divide correctamente en el discurso (por medio de las sílabas), en la modulación [medida], por el arsis y tesis"). (GS I, 80b). 
"Verum numeri genera sunt septem. Primum de temporib us longis et bre vibus. Tempus est, scilicet praesens, quando incohatur cantinela, quod in morem athomi, id est, insecabilis, nec partes nec momenta recisionis, id est, divisionis, admittit, recipit ut est in Geometricis punctum, inArithmeticis monas, id est, singularis quedam natura ac seipsa contenta, id est, sufficiens. Sed numerus in v erbis, scilicet invenitur (per syllabam, in modulatione), per sonum, id est, tonum ipsum, aut per spatium, id est, divisionem toni, quod fuerit singulare, scilicet, in venitur, id est, indi visibile et unum: maius spatium $\mathrm{v}$ ocatur systema, minus diastema". In gestu, scilicet fit tempus, per incipientem corporis motum, quod schema diximus, id est, figuram, ut in aptatione membrorum. Atque sic erit bre vissimum tempus, id est, praesens, quod insecabile memoravi. Compositum vero, scilicet tempus, id est artificiale, quod potest dividi, scilicet in species, et quod a primo, scilicet, praesenti tempore, quod est insecabile (aut duplum, aut triplum aut quadruplum) est a primo, scilicet a prima di visione [...] potest et alia ratione intelligi, ut duo tempora unius long ae syllabae pro uno tempore accipias, ac sic non solum numerus syllabarum, $\mathrm{v}$ erum etiam temporum quaternarium non transgreditur numerum, atque ei, scilicet numero, id est quaternario finis est; sicut in creatura ipse quaternatius terminus est, quod ad e xemplar eius omnis creatura formata est [...] sicut senarius numerus numerorum omnium primus est [...] nam $\propto$ quaternario et membris suis denarius conficitur numerus, unum quippe et duo et tria et quatuor decem fiunt, id est, monas, dyas, trias, tetras".

("Ciertamente, los géneros del número son siete. En primer lug ar, de los tiempos lar gos y bre ves: Tiempo es, a saber, el presente, cuando comienza la cantilena, que como un átomo, es decir, indivisible, sin partes ni momentos partibles o di visibles, admite y recibe lo que es, en geometría, un punto, en aritmética una mónada, es decir una cierta naturaleza singular y encerrada en sí misma, es deçisuficiente. Pero, el número, a saber, se encuentra en las palabras (por medio de las sílabas, en la or ganización), por medio del sonido, es decir, el tono mismo, o por medio del espacio, es decir, de la división del tono, se encuentra como si fuera singular, es decir, indivisible y un espacio mayor se denomina sistema, el menor diastema. Con el gesto [danza] se indica el tiempo, a saber, por medio del movimiento inicial, que antes denominamos esquema, es decir, figura, como en la adecuación de los miembros [del cuerpo]. Y así será tiempo brevísimo, es decir, presente, que denominé impartible. El tiempo, a saber, compuesto, es decir, artificial, es el que puede dividirse, a saber, en especies, y que desde el presente o primer tiempo, que es indivisible (o duple, triple o cuádruple) parte del primero, es decir de la primera división [...] y puede ser entendido, por otra razón, como si tomaras dos tiempos de una sílaba lar ga por un tiempo, y así no sólo el número de sílabas, sino también el tiempo cuaternario [cuatro tiempos] no trasgrede el número, sino que para el número el cuaternario es el fin [del tiempo], como para lo creado el cuaternario es el final, porque a ejemplo suyo ha sido formada toda criatura [...] como el senario es el primer número de todos los números [...] porque del cuaternario y sus miembros [partes integrantes] surge el número diez, porque uno más dos, más tres, más cuatro suman diez, es decir, monas, dyas, trias, tetras"). (GS I, 81 a).

Aureliano de Reomé in $^{2}$ (siglo ix). Su tratado Musica Disciplina cuenta como el primero, que se ocupa de la música eclesiástica partiendo de la práctica musical de su época. Define la música como San Isidoro: musica est scientia recte modulandi sono cantuque congrua ("Música es la ciencia de modular [medir] bien, con coherencia de sonido y canto") ( GS I, 30 b). Di vide la música en " mundana [cosmos: referida al cielo y la tierra], humana [microcosmos: referida al hombre], e instrumentalis [instrumentos: órgano, cítara]". Siguiendo a San Agustín, Casiodoro o Isidoro de Se villa, divide la musica humana en

32 -Aureliani Reomensis: Musica Disciplina (GS I, 27 ss.). 
tres partes: harmonica [sonidos agudos y graves], rhythmica [requiere la colaboración de las palabras; el ritmo es similar a los metros; es la medida de las palabras, no en razón de los metros, sino en el número u orden de las sílabas, que requiere el sentido del oído, como los versos ambrosianos; metrum es razón con medida; rhythmus, medida sin razón]; y metrica [medida según los metros].

Aureliano aporta un nue vo concepto de música métrica, apo yándose en Nicómaco ${ }^{33}$, en el que aparecen importantes matices, referentes a la "medida" musical ( Mensura sine ratione, Medida sin razonar), fundándose directamente en el ritmo del idioma, ob viando la cuantidad de las sílabas, y dejándose guiar por una scintilla perparva (pequeña chispa o luz) que todos llevamos dentro de nosotros en el sentimiento:

"Quot habeat humana musica partes: [...] tres: harmonica, rhtyhmica et metrica: Harmonica est, quae discernit in sonis acutum et gravem et accentum; [...] Rhythmica est quae incursionem requirit verborum, utrum sonus bene an male cohaereat. Rhythmus namque metris videtur esse consimilis: quae est modulatio verborum compositio, non metrorum «aminata ratione, sed numero syllabarum, atque a censura diiudicatur aurium, ut pleraque Ambrosiana carmina. Unde illud: Rerum / aeter / ne Do / mine; Rerum / crea / tor om / nium; ad instar metri iambici compositum, nullam tamen habet rationem, sed tantum concentus est Rhythmica modulatione. Qui scintillam [chispa] vel perparvam [atómica] habet metrorum, hic cognoscere valet nostrum de hac re sermonem. Etenim metrum est ratio cum modulatione; shthmus vero est modulatio sine ratione, et per syllabarum discernitur numerum. Metrica est, quae mensuram di versorum probabili ratione cognoscit metrorum, verbi causa heroicum, elegiacum, sapphicum, et caeterorum metrorum".

("Cuántas partes tiene la música humana: [...] tres: armónica, rítmica y métrica: Armónica es la que distingue el sonido gra ve, agudo y el acento; [...] Rítmica es la que requiere la participación de las palabras, o si el sonido se adecua bien o mal. Pues el ritmo parece ser semejante a los metros: lo cual es una composición modulada (medida) por las palabras, e xaminada no por la razón del metro, sino por el número de la sílabas, que es juzgada por la censura de los oídos, como la mayoría de las composiciones de San Ambrosio. Como aquél: Rerum / aeter / ne Do / mine; Rerum / crea / tor om / nium; compuestas, siguiendo el metro yambo, sin embar go, no están hechas se gún la razón (le yes), sino que el canto sólo tiene una "medida" rítmica. Quien posee la chispa (el sentir) de los metros, ése puede entender nuestra explicación de este tema. Metro es razón con medida; ritmo es medida sin razón, y por la sílaba se discierne el número (ritmo). Métrica es la que conoce la medida de los di versos metros por la razón probable, por ejemplo, el heróico, elegíaco, sáfico y los restantes metros”). (GS I, 33 b).

33 Nicómaco de Gerasa (Nicomachus: siglo II; teórico árabe o judío, platónico pitagórico, ecléctico. Escribió en grie go. Ejerció gran influencia en los teóricos latinos y grie gos tardíos y medievales. Todavía es citado (Nicomachus) por J. G. WALTHER en Musikalisches Lexikon (Leipzig, Wolfgang Deer, 1732, p. 442). Ense guida fue traducido al latín, entre otros, por Apuleyo ( siglo II) y Boecio (siglo v). Muy comentado por los neopitagóricos: Su "introducción a la aritmética" ( aritmetiké eísagogé) cuenta como el primer tratado que se aparta totalmente de la geometría y fue usado, hasta el siglo XIII, como libro de texto en las escuelas. Su "manual de armonía" (enxeiridion ármonikês) se basa en Pitágoras y Aristógenes (citado por Boecio, Casiodoro, Aureliano de Reomé [GS I, 34 a], etc.). Los números musicales o armónicos se fundan en las proporcionesXII. IX. VIII. VI (epitritus o sesquitercia: $12 / 9$ u 8/6 [= 4/3]; sesquiáltera o diapente: 9/6 ó 12/8 [=3/2]; diapason: 12/6 [=2/1]; y sesquinona, epgodus o tono: 8/9). El paso del sistema grie go heptacordal (escala de siete notas: A-g) al octocordal (ocho notas: A-a), o su generalización, se debe principalmente a Ptolomeo y Nicómaco. En Nicómaco están las raíces de la tendencia aritmética y metafísico-ale górica de la estética musical medieval. Precisamente los dos principales representantes de la cultura antigua en el mundo medie val, Boecio y Casiodoro, conectan directamente con Nicómaco, junto a Ptolomeo. C Cfr.: -Mathiesen, Thomas J.: "Nikomachos von Gerasa", en Die Musik in Geschichte und Gegenwart. 2a edición. "Personenteil, vol. 12". Kassel, Bärenreiter, 2004, columnas 1125-1130. Cfr. también: "Nikomachos von Gerasa", en Lexikon der Antike, Philosophie Literatur Wissenschaft. Vol. 3. Munich, Deutscher. Taschenbuch Verlag [dtv], 1969, p. 242. 
"Igitur secundum Nicomachum tertia pars humanae musicae, quae metrica nuncupatur, quoniam non tamen speculatione ac ipsius ratione, quam naturali instinctu fertur ad carmen; ideo a musica, quamquam $\mathrm{ab}$ ea originem trahat, segregandam putat".

("Por consiguiente, se gún Nicómaco, la tercera parte de la música humana es denominada métrica, no tanto por la especulación y razón, como por el instinto natural , nos lleva al poema; por lo tanto, [Nicómaco] piensa, que, aunque tenga su origen en la música, ha de ser separada de ella"). (GS I, 34 a).

Al tratar de la máxima concordancia, que debe haber entre la música y el número (cap. vi: Quod habeat musica cum numero maximam concordantiam; GS I, 35 b), insiste en que, en la música rítmica, la melodía debe discurrir de acuerdo con la naturaleza de las palabras, es decir, en consonancia con el ritmo del lenguaje y el sentido de la frase. En la música métrica, sin embargo, la medida está ya fijada por el metro (tipo de verso).

En la música, todo se explica por medio de los números (GS I, 41 a):

"Dicunt enim omnes musicae artis rationes e x numeris constare. Computus computi, id est, numerus. Computus computus, id est numeratio [...] Apud graecos arithmos; apud e gyptios Lacerb us; apud latinos, computus vel numerus vocatur [...] Philosophia tres partes: Ph ysica, ethica. Logica. [...] Apud latinos: Philosophia naturalis, moralis et rationalis. Philosophia naturalis quatuor traditur artib us: Arythmetica, Geometria, Musica, Astronomia: Arithmetica quippe de illis constat numeris, qui stabiles sunt et inteligibiles. Geometrica v ero stabilis et sensibiles habet numeros. Musica autem numeri aeque intelligibiles, mobiles tamen, et ad aliquid pertinentes. Astronomia quoque mobili et semper sensibili ratione versatur".

("Dicen, pues, que todas las razones del arte musical se fundan en los números. Cómputo significa número. Cómputo significa numeración [...]. Se gún los griegos arhitmos, se gún los egipcios Lacerbus: según los latinos se denomina cómputo o número [...] La filosofía tiene tres partes: física, ética. Lógica [...] Según los latinos: filosofía natural, moral y racional. La filosofía natural se nos ha transmitido en cuatro artes: Aritmética, Geometría, Música, Astronomía: La aritmética consta de aquellos números que son estables e inteligibles. Geometría consta de números estables e inteligibles. La música sin embar go, de números inteligibles pero mo vibles y relacionados a algo. La Astronomía, sin embar go, trata de lo móvil y siempre sensible a la razón").

Dice que el sonido (sonus), en su época, es una señal (signum) que significa para los músicos, lo que el punto para los geómetras. Para los aritméticos, sonido es el uno, esto es, la unidad:

"Sonus quippe tanti apud nos (musicos) quanti in Geometricis signum, id est, punctus, in Arytmeticis singulum, id est unitas".

("Sonido es para nosotros (músicos) lo que para lo geómetras el signo, es decir , el punto. P ara los aritméticos el síngulo (uno) es la unidad”). (GS I, 69).

En el siglo x (probablemente de una época anterior), la Cоммемоватіo BREVIS (GS I, 228), al definir la medida, nos informa del tipo de medida rítmica (medida suelta), en el sentido de San Agustín. ("Que canendi aequitas rhythmus graece, latine dicitur numerus".GS I, 228). "El equilibrio al cantar en griego, se denomina ritmo, en latín, número" (GS I, 228). ("Aequitate plane pulchritudinem omnem nec minus quae 
auditu, quam quae visu percipitur, Deus auctor constare instituit, quia in mensura et pondere, in numero cuncta disposuit. Inaequalitas ergo cantionis cantica sacra non vitiet, non per momenta neuma quaelibet aut sonus indecenter protendatur aut contrahatur [...] Item brevia quaeque impeditiosioria non sint, quam conveniat brevibus. Verum omnia longa aequaliter longa, brevium sit pae brevius"; GS I, 226-227). "Dios ha instituído que toda belleza natural debe constar de equilibrio (aequitate), que se percibe no menos por el oído que por la vista, porque creó todo se gún medida, peso y número. La desigualdad (desequilibrio) del canto no debe viciar los cantos sacros, el neuma o el sonido no deben alar garse o abre viarse por el movimiento [...] Del mismo modo algunas bre ves no sean más cortas de lo que con viene a las bre ves. Toda longa sea longa equilibradamente, igual la brevedad en las breves”. (GS I, 226).

El movimiento de la mano, del pie o alguna otra percusión indica el ritmo del canto (articulación, cierto orden del movimiento):

"Quae canendi aequitas rh ythmus graece, latine dicitur numerus: quod certe omne melos more metri diligenter mensurandum fit. Hanc magistri scholarum studiose inculcare discentib us debent, \& ab initio infantes eadem aequalitatis si ve numerositatis disciplina informare, inter cantandum aliqua pedum manuumve, vel qualibet alia percussione numerum instruere, ut a primae vo usu aequalium inaequalium distancia calle eos (f. pateat, eos) laudis Dei disciplinam nosse, et cum supplici de votiones scienter Deo obsequi".

("Dicha equidad al cantar se denomina en grie go ritmo, en latín número: por lo que ciertamente toda melodía ha de ser medida diligentemente, como es costumbre, a la manera del metro. Los maestros de las escuelas deben inculcarla con diligencia a los estudiantes (inf antes) y, desde el principio, informar sobre esta disciplina de equidad o numerosidad; mientras se canta, hay que indicar el número [ritmo] por medio de la percusión de la mano o el pie o alguna otra, para que, desde la primera edad, con la práctica de la igualdad y desigualdad, vean clara la distancia y conozcan la disciplina del canto divino, y ofrezcan conscientemente con súplicas sus devociones a Dios”). (GS I, 228).

\section{2.- Desde Guido de Arezzo}

Guido (siglo xi), en Micrologus (GS II, 14 b - 17 a), expone detalladamente, cómo las melodías deben componerse (cantarse) como si fueran un discurso, es decir, no ciñéndose tanto a las leyes de cuantidad, sino dejándose regir por el ritmo (número) del discurso, combinando lapalabra (como si fuera un neuma), grupos de palabras (miembro: varios neumas) o grupos de miembros (frase). Por ejemplo, el epitritus: una palabra de tres sílabas frente a otra de cuatro: Dó-mi-nus / Om-ní-po-tens. Todos estas partes o distinciones juntas constituyen la cantilena:

"Igitur quemadmodum in metris sunt litterae et sylabae, partes et pedes, ac v ersus; ita et in harmonia sunt phthongi, id est, soni, quorum unus, duo, vel tres aptantur in syllabas, ipsaeque solae vel duplicatae neumam, id est, partem constituunt cantilenae; sed pars una $v$ el pluses distinctiones faciunt [...] sitque opus est, ut quasi metricis pedibus cantilena plaudatur, et aliae voces ab aliis morulam duplo longiorem, vel duplo bre viorem [...] atque respondeant, nunc aequae aequis, nunc duplae $\mathrm{v}$ el triplae simplicib us, atque alias collatione sesquialtera vel sesquitertia". 
("Por lo tanto, a la manera que en los metros hay letras y sílabas, partes y pies, y v ersos; así en la hamonia (canto) hay tonos, es decir , sonidos, de los cuales uno, dos, o tres, se agrupan en sílabas, y éstas, solas o duplicadas, constituyen el neuma, es decir, la parte de la cantilena; pero, una parte o varias constituyen las distinciones, es decir, los momentos donde hay que respirar [...] y así se dirija la cantilena como si fuera con pies métricos, de modo que unas v oces de otras se diferencien por la tardanza doble más larga o doble más breve [...] y se correspondan, bien sea, las [agrupaciones] iguales con iguales, o las dobles o triplas con las simples, y otras de agrupación sesquiáltera o sesquitercia"). (GS II, 14 b).

Guido, en este cap. Xv del Micrologus, explica la construcción e interpretación del canto gre goriano, siguiedo al pie de la letra a M. F. Quintiliano (Institutiones oratoriae, libri XII) ${ }^{34}$. En Guido, también resuena la teoría sobre la elaboración e interpretación de la cantilena, atribuida a Odón de Clun y (Monitum, siglo $\mathrm{X}$; $c f r$. GS I, 275). El músico, escribe Guido, debe construir (organizar proporcionalmente) el canto, como el orador elabora el discurso con "pies rítmicos", de modo que, aquí f alta la cita original en latín "aunque no comprendamos la racionalidad", ya que esta manera de ordenar el mo vimiento no se rige por la cuantidad, sino por el acento silábico, aquí falta de nuevo la cita en latín "creemos que existe una razón, ya que deleita a la mente, en la que reside la razón. Aunque esto se demuestra mejor cantando, que escribiendo":

"Proponatque sibi Musicus, quibes ex his divisionibus incedentem faciat cantum, sicut Metricus, quibus pedib us faciat v ersum; nisi quod Musicus non se tanta le gis necessitate constringit, quia in omnb us se haec ars in v ocum (notas) dispositone rationabili v arietate permutat: Quam rationabilitatem etsi saepe non comprehendamus, rationale tamen creditur id, quo mens, in qua est ratio, delectatur: Sed haec et huiusmodi melius colloquendo quam conscribendo monstrantur" (GS II, 15 a - 16 a).

-“Sicque opus est, ut quasi metricis pedibus cantilena plaudatur" (Guido: GS II, 15 a).

-"Metricos autem cantus dico, quia saepe ita canimus, ut quasi ersus pedibus scandere videatur, sicut fit, cum ipsa metra canimus, in quib us cavendum est, ne superfluae continuentur neumae dissylabae sine admixtione trisyllabarum ac tetrasyllabarum, Sicut enim Lirici poetae hos nunc ad alios adiunxere pedes, ita ut qui cantum faciunt, rationabiliter discretas ac diversas componunt neumas; rationabilis vero discretio est, si ita fit neumarum et distintionum moderata $\mathrm{v}$ arietas, ut tamen neuma neumis et distinctiones distinctionibus quadam semper similitudine sibi consonanter respondeant, id est, ut sit similitudo dissimilis, more perdulcis Ambrosii”. (Guido: GS II, 16 b).

("Propóngase el músico, por qué divisiones de estas debe porceder el canto, como el métrico, con cuántos pies debe componer el v erso; si bien el músico no se ciñe tan necesariamente a las leyes, porque, en todo, este arte se transforma en la razonable ariedad y disposición de las voces (notas, sonidos). Aunque no comprendamos muchas veces dicha razonabilidad, lo racional cree en aquello, con lo que la mente, en la que está la razón, se deleita: pero esto lo entendemos mejor hablando que mostrándolo por escrito"). (GS II, 15 a - 16 a).

-(“Así que hay que actuar, dirigiendo con palmas la cantilena, casi como si lo hiciéramos con pies métricos") (GS II, 15 a).

34 -Pothiers, Dom Joseph: Les mélodies grégoriennes. París, Stock Musique, 1980 [= Tournai, Desclée Lefebvre, 1880], pp. 175 ss. Pothiers se ocupa profundamente de este tema "relación discurso oratorio y discurso musical", en los capítulos 9-13 , fundándose en Cicerón, Quintiliano, Guido y Aribo Escolástico. 
-(“Digo, por lo tanto, cantos métricos, porque muchas v eces cantamos de tal manera, que parece que estamos midiendo pies de v ersos, como se hace cuando cantamos los mismos metros, en los cuales hay que tener cuidado, que no se sig an neumas superfluos, sin admitir trisílabos o tetrasílabos. Como los poetas líricos añaden unos pies a los otros, de modo que los que hacen el canto, componen razonablemente di versos neumas discretos: La discreción (medida cierta) es realmente razonable, si de este modo se hace una moderada $\mathrm{v}$ ariedad de neumas y distinciones, para que así el neuma se corresponda siempre en semejanza y consonancia con otros neumas y la distición con las distinciones, es decir , para lograr una desemejante semejanza como hizo el dulcísimo Ambrosio") (GS II, 16 b)”.

Aribo Scholasticus, Musica (GS II, 215 b): [Aribo Escolástico ( $f$.1068-1078), monje benedictino flamenco, que tal vez viviera un tiempo en Lieja; dedicó su De Musica en 1078 al obispo Ellenhard de Freising (Baviera); contribuyó al desarrollo de la teoría modal de Occidente, enf atizando las fórmulas melódicas y las escalas para la definición del modo] Comentador de Guido, presta suma atención a la manera de proporcionar bien las melodías, fundándose en lasemejanza numérica de palabras (= neumas), miembros (= grupos de neumas), frases (= grupos de miembros) del discurso y sus distinciones (coma, punto y coma, punto), citando, entre otros, a Cicerón: "La semejanza es la madre de la asociación"

(Similitudo mater societatis est ). No obstante, se lamenta de que "este estudio se ha rele gado al más profundo olvido en nuestro tiempo, aún más, ha sido sepultado" ( Quae consideratio jamdudum obiit, immo sepulta est; GS I, 227).

Aribo intenta e xplicar, basándose en las proporciones "aritméticas", la teoría de Guido sobre la "medida", dirigida por la relación música/texto:

"Utilis expositio super obscuras Guidonis sententias. Et aliaeaces ab aliis morulam duplo longiorem vel duplo bre viorem aut tremulam habeant. Et paulo post summopere ca veatur talis neumarum distributio, ut cum neumae eiusdem soni repercussione, tum duarum $\mathrm{v}$ el plurium conne xione fiant, semper tamen aut in numero $\mathrm{v}$ ocum, aut in ratione tenorum neumae alterutrum conferantur et respondeant".

"Exposición útil sobre las oscuras sentencias de Guido. Unas notas tienen una tardanza (morula) doble más larga o doble más bre ve o acelerada. Y poco después, con gran cuidado préstese atención a tal distribución de los neumas (sonidos), de modo que se hagan neumas en la repercusión del sonido (soni), bien uniendo dos o más, pero siempre, bien sea por el número de notas o por razón de los tenores (acento) del neuma hay que articularlos o relacionarlos unos a otros". (GS II, 215 b).

Continúa después demostrando con ejemplos, cómo hay que articular el ritmo o medida al cantar , basándose en proporciones silábicas ( igual: 4-4; dupla: 4-8; sesquiáltera: 3-2, 6-4: epitritus: 4-3, 8-6), contraponiendo proporcionalmente entre sí dos miembros de una frase:

"Sicut enim metrorum plurimae sunt di visiones, quia quaedam sunt Asdepiadea, quaedam Saphica, quaedam Alchaica [...] sic melodiarum neumae plurimas habent di visiones. [...] Quae omnes pene sunt commensurabiles, b) ut in modum currentis equi v oces ad locum respirationis accedant"; GS I, 216 b). 
"Igual que existen muchas divisiones de los metros asclepiadea ${ }^{35}$, saphica $^{36}$ alchaica $^{37}$, [...], así también los neumas de las melodías tienen muchas divisiones [...], división igual [“5 sílabas frente a 5 sílabas”]: sém-en cé-ci-dit / in té-rram bó-nam; dupla frente a simple [“4/2"]: et ób-tu-lit / frú-ctum); sesquiáltera o tres frente a dos ["3/2"]: vi-rtú-tis / Dé-i; sesquitercia o cuatr o frente a tr es ["4/3"]: ve-ní-te / Be$n e-d i$-cti) etc. En los cantos bien dispuestos, todas las partes casi son conmensurables, como si las voces (sílabas/notas) cabalgaran, a semejanza del trote de un caballo, hacia el sitio (momento) de respirar . El caballo, cuando corre, fija los cascos cada vez con mayor rapidez, casi sin percibirse".

Aribo repite ad pedem litterae lo e xpuesto por Guido en Micrologus, Cap. xV, "De commoda componenda modulatione" ("De cómo ha de componerse una medida acompasada") (GS II, 14 b - 17 a).

\section{3.- MÚSICA RítMICA Y MÉTRICA: APARICIÓN DE LA NOTACIÓN MENSURAL}

Entre finales del siglo XIII y comienzos del XIV, aparece una serie de escritos de música, que "de golpe" informan detalladamente sobre la configuración de la notación mensural, es decir , e xplican simultáneamente diversos fenómenos asimultáneos, que fueron emer giendo paulatinamente durante un largo espacio de tiempo. La investigación histórica del sigloxix nos los presenta ordenados sucesiamente como una cadena de eslabones dirigidos hacia una meta (notación mensural). Si bien, las di versas notaciones musicales no deberían entenderse de ese modo, sino como hechos únicos e irrepetibles: notación premodal, modal, francona, premensural, mensural y proporcional. Gracias a dichos tratados, podemos informarnos sobre el "pasado" y el "entonces presente" de la notación musical, es decir, desde finales del siglo XII (posiblemente, bastante antes) hasta comienzos del siglo XIV. Dichos escritos, por un lado, recopilan el saber y, por otro, intentan teorizar (racionalizar) y unificar las prácticas musicales de su época. En este proceso de racionalización de la mensura musical, se impuso la métrica (razón/cuantidad: mensura certa) frente a la rítmica (sentimiento/acento: mensura non certa).

Para informarse de los cambios e xperimentados por la notación musical durante ese lar go, rico y "v ariopinto" periodo (J. de Garlandia, Franco de Colonia, J. de Muris, Ph. de Vitry, Marchetto de Padua) son de especial interés Walter Odington (De speculatione musice; CS I, 182-250); el Anonymus IV (De mensuris et discantu; CS I, 327-368); Jerónimo de Mora via (Tractatus de musica; "summula" o compilación de diversos tratados; CS I, 1-154); Jacobus Leodiensis [Jacques de Lieja] (Speculum Musicae; CS II, 193-433); Simón [de] Tunstede [de Norwich] ( Quatuor principalia musicae; CS IV, 200-298), el Libellus practice cantus mensurabilis (CS III, 46-58) ) $^{38}$, atribuido a Juan de Muris y elArs Nova de Philippe

35 Métrica aeólica, practicada por Safo y Alcayo, citada y practicada por Horacio; cfr.: "Asklepiadeen", en Lexikon der Antike, Philosophie Literatur Wissenschaft. Vol. 1. Munich, Deutscher. Taschenbuch Verlag, 1969, p. 199.

36 Endecasílabos, citados por Horacio; cfr.: "Sapphische Strophe", en Lexikon der Antike, Philosophie Literatur Wissenschaft. Vol. 4. Munich, Deutscher Taschenbuch-Verlag, 1969-1970, p. 155.

37 Eneasílabos y decasílabos, citados por Horacio; cfr.: "Alkäische Srophe", en Lexikon der Antike, Philosophie Literatur Wissenschaft. Vol. 1. Munich, Deutscher Taschenbuch-Verlag, 1969, p. 100.

38 Esta v ersión de CS, al parecer, fue elaborada por Ugolino de Urbieto (s. XIV). Existe una nue va edición crítica: - 
de Vitry (CS II, = CSM VIII, Roma 1964). Casi todos ellos fueron redactados hacia la misma época, es decir, alrededor del año $1300{ }^{39}$. Muchos de ellos hablan directamente de la práctica musical de su época. El tratado atribuído a Juan de Muris — podría decirse — ha llegado a ser, desde su aparición (principios del siglo XIV), como una constante dentro de un mundo musical cambiante, que, comenzando en el Ars Nova y enriquecido (modificado), especialmente desde el siglo xv, con la generalización de la práctica de las proporciones, ha acompañado el desarrollo de la música occidental (Ars nova; Polifonía franco-flamenca; Palestrina; Monteverdi; Gabrielli; H. Schütz; Corelli; Vivaldi; Händel o J. S. Bach) hasta mediados del siglo XVIII ${ }^{40}$.

La notación mensural parece ser producto de las dos diferentes prácticas o conceptos de medida conocidas: métrica (quantitas, longa, breve) yrítmica (numerus, accentus). En este proceso ha desempeñado un papel esencial la realidad sonora del lenguaje culto o vulg ar, con sus particulares acentos (dejes) idiomáticos, regionales o nacionales, en prosa o en verso.

Parece obvio, que el ritmo como orden del movimiento al cantar llegara a razonalizarse, explicarse y aplicarse con más claridad y precisión, apo yándose en la cuantidad (matemáticamente), que en el acento (gramaticalmente), sobre todo, si pensamos en la polifonía o en la música sin te xto. No obstante, como hemos visto, el ritmo de la poesía latino-medie val (prosas, v ersos, secuencias, himnos) y en lenguas romances (tro vadores, troberos, cantig as) terminó, en esa época (Adam de San Víctor, siglo XII), fundándose en el acento. Este repertorio poético-musical, transmitido, en gran parte, en lujosos manuscritos musicales como los de las Cantigas de Santa María, está escrito en notación neumática cursiva o cuadrada premensural. El ritmo modal (cuantidad o acento) se manifestaría, en primer lugar, en este tipo de composiciones.

La escasez de información en los teóricos de la época sobre la "música rítmica", frente a la “métrica”, se debe, según la investigación musicológica (J. Wolf, p. 200 ss.), a que elritmo musical estaba entrelazado con el te xto. Algunos piensan, que dicha práctica rítmica estaba tan generalizada, que los teóricos la daban por supuesta; otros opinan, sin embargo, que la notación de los siglos XI y XII no estaba aún capacitada para expresar el ritmo musical.

La polifonía medieval pudo desarrollarse gracias a la elaboración y aplicación de una medida eacta (mensura certa), basada en la longitud (cuantidad) de las figuras musicales. No obstante, bajo dicha

\footnotetext{
Berkthold, Christian, ed.: Ars practica mensurabilis cantus secundum Iohannem de Muris. Munich, Bayerische Akademie der Wissenschaften, "Veröffentlichungen der Musikhistorischen Kommission, Band 14", 1999.

39 Sobre una nue va revisión de la datación de los "tratados de música" ( CS I-IV, GS I-III, etc.), citados en este trabajo, véase: -S ACHS, Klaus-Jürgen: “Anonymi. B. Einzelhinweise auf anon yme musiktheoretische Schriften [...]. III. Lateinische und volkssprachliche Texte aus Mittelalter und Renaissance ", en Die Musik in Geschichte und Gegenwart. 2a edición, "Sachteil 1". Kassel, Bärenreiter, 1994, columnas 606-619.

40 -WaLther, Johann Gottfried: "Muria (Johannes)", en Musikalisches Lexikon. Leipzig, Wolfgang Deer, 1732 [ed. facsímil: Kassel, Bärenreiter, 1953], pp. 427-428. -M IEHLING, Klaus: Das Tempo in der Musik von Barock und Vorklassik. Wilhelmshaven, (Noetzel), 1993, pp. 21-30. En el mismo sentido, cfr.: -SEIDEL, Wilhelm: "Rhythmus, Metrum Takt, IV, 4. Barock (1600-1750)", en Die Musik in Geschichte und Gegenwart. 2a edición. "Sachteil 8". Kassel, Bärenreiter, 1998, col. 283. El tratado Musica speculativa de Juan de Muris fue usado (B. N. Vincentino, lo alaba como el creador de la música mensural) como manual escolástico en lasfacultades de arte alemanas hasta el año 1550;cfr.: -DahlHaus, Carl; y EgGeBrecht, Hans Heinrich, eds.: "Muris, Johannes de", en Brockhaus Riemann Musik Lexikon, vol. L-Q. Munich, Erw. Taschenbuchausgabe, 1989, pp. 169-170.
} 
mensura cuantitativa, aparecen en las composiciones ritmos muy complejos, mezclados o combinados, en los que late claramente el ritmo suelto del lenguaje (bisílabo, trisílabo, etc.). Esto se aprecia, por ejemplo, cuando los compositores entrelazan o contraponen grupos binarios y ternarios en la mensura de longa perfecta con tiempo imperfecto (= 3 bre ves binarias: tríbraco: breve-breve-breve; yambo: brevelonga; troqueo: longa-breve; coriyambo: breve/semibreve-semibreve/breve), o en la de longa imperfecta con tiempo perfecto (= 2 bre ves ternarias: yambo: semibre ve-breve/semibreve-breve; troqueo: bre vesemibreve/breve-semibreve; coriyambo: breve-semibreve/semibreve-breve; hemiola (figuras con color): breve/semibreve-semibreve/breve), etc. De ahí, que, en el sigløıv, fueran necesarias lasseñales de medida, para indicar el modo (mayor o menor: 3, 2), tiempo (perfecto o imperfecto: O, C ) y prolación (mayor o menor: presencia o ausencia del punto en las señales), con sus respecti vas modalidades (perfección, imperfección, proporción, etc) y combinaciones.

El Anónimo iv (CS I, 327-365) trata de la notación musical desde la época de la escuela de NotreDame de París (1160-1180) o, posiblemente, desde tiempos anteriores. Su autor explica detalladamente la medida (mensura), basándose en conceptos comomodus, tempus, longitudo (longa), brevitas (breve), etc., usuales en la métrica latina (modos rítmicos: yambo, troqueo, dáctilo, etc.). También se ocupa del color (carácter, adorno) y ordo (estructura de los modos rítmicos) del canto (meli):

"Nunc habendum est de mensuris eorumdem [melorum octo troporum], secundum longitudinem et brevitatem prout antiqui tractaverunt".

("Ahora se ha de tratar de sus [las melodías de los ocho tonos] mensuras, como trataron los antiguos, según la longitud y brevedad"). (CS I, 327 b).

Describe detalladamente las notas (sonus, figura, longa, brevis, semibrevis, figura simplex, ligata, etc.) y su duración (binaria, ternaria, perfecta, imperfecta, etc.), partiendo de los tradicionales conceptos métricos modus (medida basada en una serie o esquema de figuras o neumas ordenados)y tempus (medida basada en una determinada figura musical: breve):

"Modus vel maneries vel temporis consideratio est cognitio longitudinis et brevitatis meli sonique". ("Modo o manera o consideración del tiempo es el conocimiento de la longitud o bre vedad de la melodía y de la figura musical”). (Cs I, 327 b).

"Longa simplex continet duo tempora [...] Bre vis simplex est quod continet unum tempus [...] Sonus [nota, figura] sub uno tempore potest dici sonus acceptus sub tempore non minimo, non maximo, sed medio legitimo breviter sumpto, quod possit frangi v eloci motu in duob us, tribus, vel quatuor, plus in voce humana, quamvis in instrumentis possit aliter fieri”.

("La longa simple contiene dos tiempos [...] La breve simple es lo que contiene un tiempo [...] La nota [figura] como tiempo puede denominarse nota definida [aceptada usual o tradicionalmente] como un tiempo ni mínimo, ni máximo, sino en su le gítimo medio tomado bre vemente, que puede di vidirse por movimiento veloz en dos, tres o cuatro, hasta ahí en la v oz humana, aunque en la música instrumental puede hacerse de otra manera"). (CS I, 328 a). 
Define el ordo modi de la manera siguiente:

"Ordo modi est numerus punctorum ante pausationem". (CS I, 328 b).

(“Orden del modo es el número [esquema rítmico] de las notas [puntos] antes de hacer la pausa").

El ordo a viene ocupar el lugar intermedio entre el pes y el versus, es decir, el metrum de la poesía latina, según San Agustín.

Al explicar los modos, aunque se basa en el concepto de tiempo largo o breve, tiene presente constantemente la relación de las notas musicales con las sílabas del texto, especialmente, al tratar del aumento o disminución (distractio) en la duración de las notasAhora bien, en esta época, si lassecuencias (prosas) se cantaban apo yándose en el acento silábico, podría suponerse, que éste sería también un elemento importante respecto a la articulación o dirección de la medida. La combinación o mezcla de pies (binarios, ternarios) parece recoger el ritmo suelto del lenguaje:

"Notandum quod differentia est dicendo cum littera et sine littera [...] Cum littera ero quandoque fit ligatio quandoque non; sed in maiori parte plus distrahuntur , quam lig antur Unde re gula: Omnis simplex figura, prout se ostendit sub uno nomine, elong atur vel abbreviatur. Distractio est propter syllabas subpositas, quoniam supra quamlibet syllabam quandoque ponitur [...] Et ratione syllabarum, secundum aliquos, quilibet punctus absolutus dicitur, prout non reducitur ad f iguram ligatam".

("Se ha de observar, que existe diferencia entre lo que se canta con letra y sin letra [...] Con letra, unas veces se ligan las notas y otras no; en la mayor parte de los casos se desligan más, que se ligan. De ahí la regla: toda figura simple, tal como se nos manifiesta por su nombre, se alaga o se acorta. La prolongación o abreviación se debe a las sílabas que están debajo, puesto que, a v eces, se pone sobre cualquier sílaba [...] Y según sean las sílabas, se gún algunos, cualquier nota se denomina absoluta, en tanto que no es agregada (unida) a la ligadura"). (CS I, 343 a).

Hacia finales del siglo xiII, el tratado Fratris Walteri Odingtoni De speculatione musice (CS I, 182-250 $)^{41}$, define doblemente la música, apoyándose en definiciones del pasado.

En la primera parte, se ocupa, dada su importancia para la música, de la aritmética ( arsmetrica: sonidos, armonía) y de la estructura métrica e interpretación (medida de duraciones, basada en proporciones: igual, desigual, etc.) de los pies simples como el espondeo (longa-longa), el pirriquio (bre ve-breve) "muy frecuente en las competiciones y jue gos de niños"; o de la combinación de pies métricos como el coriyambo (longa-breve/breve-longa) "muy apto para los coros":

"Musica est pertractatio [...] de numero relato ad sonum, prius de arsmetrica arbitrorArsmetrica autem nominis interpretatione est scientia de numero".

41 Nueva edición por Fr. H. Hammond en csm XIv. Roma, Fr. H. Hammond, 1970. (W. Odington pertenece a la osB, 1277c, es inglés, $f$ l. Oxford, fue matemático y teórico musical. Su tratado es de 1316c, aunque reproduce la situación de 1300c. 
("Música es el estudio [...] del número relacionado con el sonido, opino que antes hay que tratar del arte-métrica: Arte-métrica, pues, se gún la interpretación de este nombre, es la ciencia del número [la medida]"). (CS I, 183 b).

En la segunda parte del tratado, define la música comomodulationis peritia sono tactuque consistens, ("Pericia en la medida al sonar y tocar"), repitiendo la definición de San Isidoro (GS I, 20 a). El cambio del término cantuque por tactuque, puede ser una errata.

Divide la música, de acuerdo con la tradición (Casiodoro, Isidoro), en tres partes: 1) orgánica, 2) rítmica o métrica, y 3) armónica.

Al principio del tratado se ocupa de larsmétrica [sic] (aritmética: números, proporciones, intervalos, etc.) como fundamento de la música. Como San Agustín, aplica las proporciones numéricas a los pies métricos.

Después trata de la música armónica, que divide en: simplex (canto llano) y multiplex (polifonía). En el apartado sobre la musica simplex, explica las figuras musicales (punctum, vir ga, neuma, etc.), que reciben su v alor (longa, bre ve) del texto. En el correspondiente a la musica multiplex, describe las figuras musicales (longa, breve, semibreve y minuta) y su aplicación a los modos rítmicos, como también sus posibles combinaciones y di visiones, usando la terminología heredada de la métrica latina (yambo, espondeo, coriyambo, etc.).

Al decir "rítmica o métrica", indica, que ambos términos tienen para él un significado idéntico, es decir, ambas músicas se basan en el número (San Agustín), como medida.

En la música armónica (canto llano y polifonía), lo importante es la relación directa con el lenguaje, bien se trate de "prosa (incursionem verborum) o verso (de gestis et carminibus)"42.

"Exponendum que est de numero per se sine qua quidquid nequit pertractari [...] Musica rithmica seu metrica est que requirit incursionem $\mathrm{v}$ erborum et decernit in gestis et carminib us (poemas), aut pedes, quibus constat apte cohereant".

("Se ha de exponer lo que es el número per se, sin lo cual es imposible estudiar (tratar) cualquier cosa conocida. La musica es or gánica, rítmica o métrica y armónica. La música orgánica consiste en los instrumentos musicales; la rítmica o métrica es aquella que requiere la concurrencia de las palabras y es determinante en la narración de hechos históricos (épica) y en los poemas (lírica), o que los pies, de que consta, se adecuen coherentemente. La armónica requiere la cohesión (modulación, medida) de voces y muchos sonidos y pertenece a aquellos que cantan con su propia v oz"). (CS I, 193 a).

42 Simon deTunstede (mediados del sigloxiv), en Quatuor principalia musicae,(cs IV , 202) distingue entre músicarítmica $y$ metrica, ambas directamente relacionadas con el lenguaje: "Rithmica $\mathrm{v}$ ero est illa quae in scantione requiritur utrum bene $\mathrm{v}$ el male cohereant dictiones, quod cantando utendum est canendo [...] Metrica est illa quae mensuras di versorum metrorum ostendit probabili ratione, ut patet in eroico, iambico et ele giaco metro" (CS IV, 202). En la definición de música armónica re vela detalles importantes sobre la medida: (“ Musica harmonica est illa que consistit in numeris; et hoch dupliciter; una localis secundum proportionem sonorum et vocum in quantitate continua; alia temporalis secundum proportionem longarum, breviumque figurarum in quantitate discreta") "Música harmónica es aquella que se basa en los números; y esto de doble manera; una local se gún la proporción de los sonidos y v oces en cantidad continua [aritmético-numérica: interv alos, consonancias, multitud]; otra temporal según, la proporción de longas y breves en cantidad discreta [geométrico-cuantitativa: magnitud]”. (CS IV, 202 b). 
Son de gran interés, respecto a la relación música/lenguaje, mensura/directio mensurae, etc., los matices que aporta su explicación de tempus (movimiento de la sílaba o pulso):

"Rhytmus non est certo fine moderatus; sed tamen rationabiliter ordinatis pedib us currit. Pedes sunt qui certis syllabarum temporib us insistunt. Et tempus quidem est mensura motus syllabae, ut cum solum pulsum habeat syllaba dicatur long a duorum temporum. Accidit autem unicuique pedi arsis et thesis, id est ele vatio et depositio que sunt tempore mensurate. Et secundum inequalitatem temporum accidit inaequalitas habitudinis ele vationis comparate ad depositionem, ut patebit [...] Si vero breves sunt arsis et thesis, dicitur pyrriquius sic (BB), ideo dictus quod certamine vel ludo puerili frequentetur".

("Rhytmus es lo que no es medido con un final cierto; pero, sin embar go, razonablemente, corre con pies ordenados. Los pies indican los tiempos ciertos de las sílabas. Tiempo es la medida del movimiento de la sílaba, de modo que si la sílaba se pronuncia con un solo pulso se denomina long a de dos tiempos. Sucede, por lo tanto, que a cada pie le corresponde arsis y tesis, es decir , elevar y caer [el alzar y el dar], que se mide por el tiempo. Y según la desigualdad de los tiempos, sucede una cierta desigualdad al elevar (al alzar) con relación al caer (al dar), como quedará claro. [...]. Si el arsis y la tesis son breves, se donomina pirriquio, así: (bre ve-breve); es denominado de esa manera, porque es frecuente en los certámenes y juegos de niños”). (W. Odington: CS I, $211 \mathrm{a}$ ).

Continúa, después (De illis pedibus quorum elevatio equalis est depositioni.- De dupla inaequalitate in pedibus.- De tripla inaequalitate.- De sesquialtera.- De sesquitertia.- CS I, 211 a ss.), e xplicando los pies métricos y su medida por medio del arsis y tesis ( elevatio et depositio), siguiendo a San Agustín: dos tiempos largos (dos longas, una al dar y otra al alzar) es un espondeo (que suena lento o pesado); dos tiempos breves (una al dar y otra al alzar) es un pirriquio, que se denomina así, porque es frecuente en los certámenes y juegos de niños. Explica también la duración de las figuras, en su época (1300c), en comparación con la de épocas pasadas:

"Et inequalitas temporum in v ocibus consonantibus, sicut sequitur, que notis exprimitur [...] Ita igitur inequalitas accidit, dum una nota morosius et alia elotius profertur. Morosa longa vocatur que prius virga dicitur nota, scilicet: quadrata cum tractu a parte de xtra [...] Velox vero vocatur brevis, que prius dicitur punctus; figura scilicet quadrata".

("La desigualdad de los tiempos en las voces consonantes, como sigue, que se expresa en las notas [...] Por lo tanto, la desigualdad se produce del modo siguiente: cuando una nota se emite mas lenta y otra más rápida. La lenta se denomina longa que antes se denominaba virga, es decir, cuadrada con una plica en la derecha [...] Rápida se denomina la breve, que antes se denominaba punto: es decir, la nota cuadrada"). (CS I, 235 a).

"Longa autem apud prior es organistas duo tantum hab uit tempora [br eves], sic in metris ; sed postea ad perfectionem dicitur, ut sit trium temporum ad similitudinem beatissime trinitatis [...]. Illa ero que tantum duo habet tempora dicitur imperfecta".

(“La longa, por lo tanto, según los antiguos organistas sólo constaba de dos tiempos, así en la métrica; pero posteriormente se dice que por la perfección, constaba de tres tiempos a semejanza de la beatísima trinidad [...]. Aquella que consta de dos tiempos se denomina imperfecta"). (CS I, 235 b). 
Continúa su exposición, explicando que, cuando la longa se divide en dos breves, la primera se denomina breve recta y la segunda áltera. La brevis recta vale la tercera parte y, la brevis altera, dos terceras partes de una longa perfecta. La breve se divide en tres o dos semibreves. Cuando la breve se parte en dos semibreves, la primera se denomina minor (1/3) y la se gunda maior (2/3). Puede dividirse también en tres semibreves iguales. La breve recta vale un tiempo de estos:

"Recta bre vis autem [...] continens igitur unum in se tempus [...] unde v ersus: Solo recta bre vis moderatur tempore quevis".

("La breve recta vale por lo tanto un tiempo, como dice el v erso: sólo la breve recta es medida por un tiempo como este"). (CS I, 235 b).

También se refiere a figuras inferiores a la semibreve, denominadas "minutas".

La breve se pinta como un cuadrado de ángulos y lados iguales; la semibreve, en cambio, con lados iguales pero con ángulos desiguales (rombo).

El tratado concluye explicando las formas polifónicas de su época: organum (purum et discantus), rondellus, conductus, copula, motetus y hoquetus.

Jerónimo de Moravia: Su Tractatus de Musica (CS I, 35 b, 36 a), escrito hacia finales del siglo XIII, es considerado como una summula del saber musical de su época. Explica, en primer lug ar, citando a Boecio, que la filosofía trata de lo inmutable, pero, cuando lo inmutable se relaciona con lo mutable (materia musical, sonido) suceden cambios sorprendentes:

"Formas, magnitudines, qualitates, relationes, habitudines, et cetera, que per se speculata, inmutabilia sunt"; "juncta $\mathrm{v}$ ero corporib us, permutantur, et multimodis $\mathrm{v}$ ariationibus mutabilis rei cognatione vertuntur".

("Las formas, magnitudes, cualidades, relaciones, hábitos, etc., que, contemplados per se, son inmutables; cuando éstas se unen verdaderamente a los cuerpos, cambian completamente y, debido a las múltiples variaciones, crean un parentesco con las cosas mutables"). (CS I, 35 b, 36 a).

En la época de J. de Mora via, la música se consideraba como una scientia operativa (activa, práctica). Uno de sus objetivos era el estudio de las relaciones entre el número y el sonido (musica est numerus relatus ad sonum ). Una ciencia, por lo tanto, que presupone el conocimiento de la aritmética. Como San Agustín, Jerónimo de Mora via, antes de entrar en el estudio de los tonos eclesiásticos, dedica los capítulos XVI-XXI del tratado al estudio del número y sus relaciones. Comienza usando los términos "número o cantidad" con un signifcado semejante (número: unidad/ suma o cuantidad: todo/parte):

"Omnis v ero quantitas, secundum Pythagoram, v el continua v el discreta est. Sed que continua est magnitudo appellatur; que discreta est multitudo".

(“Ciertamente, toda cantidad [número], seún Pitágoras, es continua o discreta. La continua se denomina magnitud; la discreta multitud"). (CS I, 36 a). 
En J. de Moravia resuena la teoría del Musica Enchiriadis. La parte tercera de este tratado (Incipit Tertia, GS I, 196) comienza explicando, qué es cuantidad:

"Quantitatem dicimus \& in numerib us, \& in mobilib us. Nam quantitas numerabilis proprie dicitur multitudo, quae unitatibus congregatur. Quantitas specialis, que in mobilibus fit, dicitur magnitudo, que in unitates dividitur. Nam multitudo [quantitas numerabilis] infinita pluralitate succrescit, magnitudo infinita partitione minuitur. Hoc est, multitudo ad unum e x pluralitatibus tendens augetur spatio; magnitudo ab uno in pluralitatem tendens unitatum spaciis minuitur , utope lapis [...] quo minore di viditur numero, divisionum spacia maiora sunt; quo autem in plura partiuntur eo ipsa minuuntur spacia: ut verbigracia de viginti quatuor dimidium duodecim, pars tertia octo, pars quarta se $\mathrm{x}$ [...] Utrarumque ergo similitudine quantitatum aritmética ex sese musicam fundit".

("Denominamos cuantidad respecto a los números y a lo móvil. Pues cuantidad numerable se denomina propiamente la multitud, que se compone de unidades. Cuantidad especial, que es la de lo móvil, se denomina magnitud, y se divide en unidades. Pues la multitud (cuantidad numerable) crece en pluralidad infinita, la magnitud disminuye en división infinita. Es decir, la multitud crece en espacio tendiendo hacia el uno, compuesto de pluralidad. La magnitud disminuye en espacio desde el uno en pluralidad tendiendo a la unidad, como una piedra [...] cuanto menor es el número parcial, mayor es su espacio, y cuanto mayor es el número de parte menor es el espacio. Como la mitad de veinticuatro es doce, la tercera parte es ocho, la cuarta parte es seis. La música se funda en la semejanza aritmética de las cuantidades"). ( GS I, 196).

Numerus o quantitas, aunque, en principio, tienen un signif icado semejante (arítmética/ geometría: contar/medir), numerosos teóricos medie vales de música, establecen diferencias entre ambos términos, en tanto que, por numerus, entienden una serie continua, abierta o aditi va, ininterrumpida (por ejemplo, I; I + I = II; I + I + I = III; I + I + I + I = IIII; etc.), es decir, una multitud (agregación de unidades: IIII = I + I + I + I); y, por quantitas, sin embargo, una serie discreta, cerrada en sí misma (por ejemplo, IIII es un cuadrángulo) es decir, una magnitud máxima, larga, breve o mínima, divisible en cuatro partes. Si el numerus como unidad definida racionalmente, por ejemplo el número "IIII", es la suma de cuatro unidades, una quantitas como unidad definida racionalmente, por ejemplo, un cuadrángulo (longa), es una magnitud (un todo) divisible en partes (bre ves). Ambos conceptos como sistemas de medida se fundan en principios análogos: ehumérico en sumar (agregar) elementos indi viduales (singula, unidades) y crecer ad infinitum, y el cuantitativo, en dividir magnitudes (f iguras) en partes ad infinitum. El numerus (multitudo) parte de la unidad indivisible (finita, mónada, singulum, el número 1), que crece, por acumulación, ad infinitum ${ }^{43}$, al contrario de la cuantidad:

43 Hucbaldi Musica Enchiriadis: Incipit Tertia ( GS I, 198 a), lo e xplica detalladamente: "Nam quantitas numerabilis proprie dicitur multitudo, quae unitatib us congregatur. Quantitas specialis [ ¿spatialis?], quae in mobilib us fit, dicitur magnitudo, quae in unitates di viditur" ("Pues la cantidad numérica se denomina propiamente multitud, que se compone de unidades. La cantidad especial [¿espacial?], que se efectúa en lo móvil, se dice magnitud, que se di vide en unidades"). 
"A finita incohans quantitate (unitas), crescens in infinita progreditur, ut nullus crecendi finis occurrat. Estque ad minimum terminata, interminabilis ad maius, eiusque principium unitas est, qua minus nihil est".

("Comenzando desde una cantidad finita [unidad numérica], que progresa creciendo hasta lo infinito, sin llegar nunca al final. Si es algo terminado respecto a lo mínimo [unidad cuantitativa], es interminable respecto a lo mayor; su principio es la unidad, sin existir nada menor que ella"). (cs I, 36 a).

El número crece, por adición, desde el uno hasta hasta el infinito; la quantitas, decrece desde su totalidad ad infinitum:

"Magnitudo rursus sue mensure recipit quantitatem, sed in infinita decrescit".

("La magnitud recibe la cantidad contra la cuantidad de su medida [total], y disminuye hasta el infinito"). (CS I, 36 a).

Según Jerónimo de Moravia:

"Numerus vero est unitatum collectio, vel numerus est multitudo ex unitatibus aggregata".

("Número es ciertamente un colección [suma] de unidades, o número es una multitud agre gada de unidades"). (CS I, 36 a).

Si el numerus como unidad (uno) es indivisible, la quantitas, sin embargo, como unidad es un todo divisible en partes. El numerus solía expresarse con letras (griegas: $a, b$, c, etc.), capitales romanas (I, II, III, etc.) o, posteriormente, con números arábigos (1, 2, 3, etc.); la quantitas se expresaba, por lo general, con figuras o signos visuales (cuadrado o long a, rombo o semibre ve, guión [larga], semicírculo abierto hacia arriba [breve], puntos, líneas, círculo, semicírculo, etc.). El número puede ser par o impar, igual o desigual, menor o mayor. La cantidad puede ser igual o desigual, lar ga, más larga, etc. (longa, longior, longissima o maxima) o corta (brevis, brevior, brevissima o semibrevis maior, minor y minima).

J. de Moravia explica los dos tipos de medida: numérica y cuantitativa:

El ars (scientia), cuyo fin es definir (racionalizar) los números (arithmos: cifras, multitud, serie continua), se denomina aritmética:

"Huius [Arithmeticae] autem subjectum est numerus simple $\mathrm{x}$ et in se acceptus et omnino abstractus. Finis autem est numeri sic considerati cognitio in se et in suis partitus ac proprietatibus".

("Cuyo sujeto [de esta Aritmética] es el número simple, aceptado en sí y totalmente abstracto. El fin, por lo tanto, es el número así considerado, el conocimiento en sí y en sus partes y propiedades”). ( CS I, 36 b).

Su “inventor" fue Pitágoras, que estableció, por medio de la proporción (relación, razón) e xistente entre cuerdas o pesos diferentes, una medida justa, fundada en la razón y el sentido (el oído).

El ars (scientia), cuyo fin era definir (racionalizar) las cantidades indefinidas (figuras, superficies, magnitudes), se denomina geometría. Su "fundador" fue Euclides, que estableció, por medio de las 
proporciones (relaciones, razón) entre las figuras, una medida justa, fundada en el sentido (la vista) y la razón.

Jerónimo de Moravia (CS I, 35 a) trata de la relación del sonido con el mo vimiento (motus). En el párrafo siguiente, se refiere al movimiento (vibración) del sonido. El sonido grave se distingue del agudo por el movimiento lento o veloz, respectivamente:

"Sonus vero preter quemdam pulsum percussionem quoque non redditur Pulsus vero atque percussio nullo modo esse potest, nisi precesserit motus. [...] Motuum $\mathrm{v}$ ero alii sunt $\mathrm{v}$ elotiores, alii tardiores, eorumdemque motuum alii sunt rariores, alii spissiores. Nam si in continuum motum respiciat, ibi aut velocitatem aut tarditatem necesse est ut comprehendat. Si quis mo vet manum, aut frecuenti eam motu movebit aut raro. Et si tardus quidem fuerit ac rarior motus, gra ves necesse est sonos effici ipsa tarditate et raritate pellendi. Sin v ero sint motus celeres ac spissi [apiñados], acutos necese est reddi sonos".

("El sonido no existe sin percusión del pulso [pulsar]. El pulso y la percusión no pueden e xistir si no precede el movimiento [...] Unos movimientos son más veloces y otros más lentos, y los mo vimientos, unos son más densos y otros más finos. Pues, si se contempla el mo vimiento continuo, es necesario comprender ahí también la v elocidad o lentitud. Si alguien mue ve la mano, la mue ve con mo vimiento frecuente o distanciado. Si el movimiento es lento y prolongado, los sonidos son necesariamente graves, debido a esa tardanza y densidad al pulsar . Si, por el contrario, los mo vimientos son acelerados, los sonidos son necesariamente agudos"). (CS I, $35 \mathrm{a}$ ).

El tempus, en principio, se gún los gramáticos, era la sílaba. San Agustín, como hemos visto, definió el tempus como número, referido a la duración de las sílabas (larga o breve). En tanto la sílaba fuese entendida comonúmero, podía ser cuantificable o mensurable según los principios de laaritmética (número: multitud, agregación de unidades) o de lageometría (cuantidad: magnitud divisible en partes: maior, minor, minima). El numerus (racionalizado, individualizado) podía sersingulum (unidad), doble, triple, cuádruple, etc., o también minimum 44 (unidad: "minima", qua nihil minus est, sed duplicata fit numerus binarius [...] ternarius. ("Porque no existe nada menor, pero duplicada hace el número binario [...] ternario") (CS IV, 261 b). La sílaba long se consideraba como "doble tiempo" (dos tiempos brees). El uno y lo mínimum eran indivisibles Musica mensurabilis incipere habet a minima crescendo, sicut numerus ab unitate, et sic unitas et minima convertuntur("La música mensural empieza a crecer desde la mínima, como el número desde la unidad, así que la unidad y la mínima son equi valentes”). (CS IV, 262 a).

44 Según el Speculum musicae: "Tempus minimum possuit Franco, cum brevis in tres semibreves dividitur [...] huius modi semibrevis de quo loquor est minima pars bre vis; minimo autem non est dare minus, nec minimum di visibile est [...] Idem igitur intelligit ibi Franco per semibrevem que tertia pars brevis perfecte, quod intelligunt moderni per minimam moderni vel athomam quam ponunt partem no vem temporis perfecti, et communiter indi visibile". ("El tiempo mínimo lo estableció Franco, cuando la breve se divide en tres semibreves [...] de este modo, la semibreve, de la que hablo, es la mínima parte de la breve; a lo mínimo no de le pueder dar menor, ni lo mínimo es divisible [...] Del mismo modo entiende ahí Franco por semibre ve la tercera parte de la breve perfecta, lo que los modernos entienden como mínima de los modernos o átomo, que ponen como no vena parte del tiempo perfecto, y comúnmente es indivisible"). (cS II, 400 b). 
En la segunda mitad del siglo XIII, el tempus es primordialmente entendido como fenómeno físico ${ }^{45}$, es decir, como "medida del movimiento [solar]" (mensura motus). Los físicos y astrónomos consideraban, que el tiempo, aunque se entendía como "morimiento continuo" (eterno retorno), podía medirse (contarse) y dividirse ad infinitum (años, meses, días, horas, minutos, instantes, átomos). Con este cambio en el modo de pensar, empezó a tambalear el tradicional concepto de tempus, racionalmente definido como "sílaba bre ve", "número uno", unidad de medida, es decir, lo mínimo (indivisible) perceptible como realidad sensible ("El tiempo es lo mínimo en la prolación o plenitud de la voz"); Tempus est minimum in prolatione seu plenitudine vocis, para ir a parar a un nue vo concepto, fundado en la división infinita, difícilmente mensurable o comprensible por la razón o, a lo sumo, meramente imaginable, como edtomo. Esta nueva especie demedida (imaginaria) era usada por los astrónomos. Pero esta "ciencia" (astronomía), según los teóricos de música de la época, no trataba de losensible, como la música, sino de lo imaginable (insensible); es decir, se ocupaba de algo situado fuera de la realidad (materialidad) musical ${ }^{46}$. Se abre

45 El Liber de musica (CS III, 130 b) de Johannes Verulus de Anagnia ( $f$ l. segunda mitad del siglo xIII; cotemporáneo de J. de Moravia), explica el tempus (físico) del modo siguiente: "Mensura est quantitas temporis determinata per ipsum tempus in quo nota profertur, unde tempus, secundum Philosophos, sic definitur: «Tempus est mora motus mutabilium rerum»; sed tempus, prout spectat ad musicam, non est tempus, sed id quod agitur in tempore, videlicet armonia cantus, et $\mathrm{v}$ ocum melodia que per tempus mensuratur" ("Medida es una cantidad de tiempo, determinada por el mismo tiempo en que se pronuncia una nota, por lo que tiempo, según los filósofos, se define así: «Tiempo es la tardanza del movimiento de las cosas mutables»; pero tiempo, por lo que se refiere a la música, no es tiempo, sino lo que se efectúa en el tiempo, a saber, la armonía del canto, y la melodía de las voces, que se mide por el tiempo"). (CS III, 130 b). A continuación, relaciona la duración de las notas con el tiempo físico:

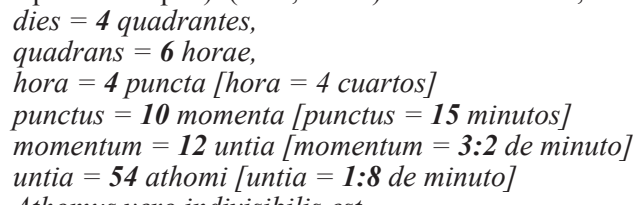

Después, al tratar "Quomodo accipitur tempos" (Cómo hay que entender el tiempo) ( CS III, 137), dice lo siguiente: "Etiam dictum est, quia musicus non accipit tempus, sed id quod mensuratur per tempora, tamen in tempore, quia tempus non est maius, neque minus, sed medium, quod est acceptum, divisum, et reductum a musico a die naturali usque ad athomum. Valor athomorum quinquaginta quatuor, et particulariter vocis viginti septem [...] sed ab isto tempore non incipiendum est di videre, sed a tempore perfecto maiore, quod continet in se vlorem athomorum septuaginta duo, particulariter vocis triginta sex, et minimarum duodecim, de prolatione maiore, et tempus perfecte maioris di visionis duodenariae majoris prolationis appellatur, quod principaliter in duas partes inaequales di viditur, et tunc prima pars erit minor , secunda v ero major, vel e contario". ("T ambién se ha dicho, que el músico no acepta el tiempo, sino aquello que se mide por tiempos, no obstante, en el tiempo; porque el tiempo no es mayor ni menor, sino medio, que es aceptado, di vidido y reducido, por el músico, partiendo del día natural hasta el átomo. El v alor de 54 átomos y, particularmente, el de 27 notas (voces) [...] pero no hay que empezar a dividir desde este tiempo, sino desde el tiempo perfecto mayor, que contiene en sí el valor de 72 átomos, y particularmente, el de 36 notas, y de 12 mínimas, de prolación mayor, y el tiempo de la división perfecta mayor se denomina de prolación mayor duodenaria, que principalmente se divide en dos partes desiguales, y entonces la primera parte será menor y la segunda mayor, o al contrario". (CS III, 137).

46 Respecto a este problema, es interesante cómo se expresa, poco tiempo después de J. de Moravia, o Simón de Tunstede (mediados del siglo XIV) en Quatuor principalia musicae (CS IV, 275 b). El autor de este tratado, dice lo siguiente: [Extracto y traduzco lo esencial]: "El tiempo perfecto se parte en tres semibreses, tanto en nueve mínimas o en aquello que contenga ese valor. [...] Algunos objetan y dicen, que, lo continuo es divisible "ad infinitum", y el tiempo es continuo; las notas ciertamente se miden por el tiempo, por lo tanto, serán di visibles infinitamente. Este ar gumento engaña a los que presumen saber música e ignoran los principios; pues, creen que la música es totalmente continua, cuando es también discreta, como se ha demostrado antes en la primera distinción del capítulo primero. El tiempo, tal como se acepta en la música mensural, como se aclaró anteriomente, en e 1 cap. 23, no es continuo sino discreto, cuya cabeza [unidad] es la mínima, que no es el tiempo, sino el principio del tiempo, como la unidad lo es del número. Dicen también, que no e xiste unidad, que no pueda di vidirse, a saber, en minutos, y los minutos en segundos, y así sucesivamente; a los cuales hay que decir que si isten minutos y segundos, como muchos son dos, o tres, o cuaro, o más, están sometidos al número y así todo lo que empieza con número comienza desde la unidad. Sin embæro estos minutos que 
paso fuertemente la especulación escolástica sobre el tiempo: el concepto aristotélico de tiempo como mensura motus ("medida del mo vimiento [o del cambio] se gún el antes y después"). ("Ex hoc enim numeramus prius et posterius in motu, apprehendimus tempus") “ Al numerar un antes y un después en el movimiento, aprehendemos el tiempo". ( CS I, 89 a). El tiempo sólo puede captarse a tra vés de "lo que sucede en el tiempo". El tiempo en sí no puede ser captado por la razón, sólo es posible entenderlo o razonarlo a través de la relación con el espacio (largo o corto) y el movimiento (lento o veloz).

Llama especialmente la atención, que, precisamente, en este momento histórico, es cuando aparecen "de golpe" todos los tratados de música, gracias a los cuales conocemos lo esencial de la denominada notación mensural, como he indicado anteriormente.

De ahí, las importantes observaciones, que hace Jerónimo de Moravia, al explicar qué es el tempus:

"Musica igitur mensurabilis est que mensuram notarum omnium probabili ratione cognoscit; $v$ el sic: musica mensurabilis est peritia modulationis sono cantuque consistens, armonico tempore mensurata. Tempus autem, prout hic sumitur , est distinctus sonus resolubilis in tres instantias. Instans v ero hic sumptus est illud minimum et indivisibile, quod in sono auditus clare ac distincte potest percipere. Quod etiam apud v eteres, dicebatur esse tempus. Sed modernorum, ut videtur , melior est opinio, qui scilicet in tempore armonico motui subjecto successionem ponunt; nam omnes transferentes secundum aliquam similitudinem transferunt. Tempus armonicum tempore naturali debet aliqualiter assimilari; sed loquendo naturaliter, successio non invenitur, nisi in illis que sunt aliqualiter motui subjecta; prius enim et posterius causant temporis successionem. Ex hoc enim numeramus prius et posterius in motu, apprehendimus tempus, quod nihil aliud est quam numerus prioris et posterioris in motu. Cum igitur tempus armonicum motui progressivo sit subjectum, oportet omnino in ipso ponere successionem trium scilicet instantiarum, quam veteres tollunt, ponentes aliquid indivisibile tempus, unam scilicet solam instantiam. Potest amen, licet improprie, instantia dici tempus, sicut et vulg ariter dicitur, nunc temporis esse quoddam tempus brevissimum; et secundum hoc quantum ad aliquid antiquorum salv atur opinio. [...] Hoc igitur tempus armonicum est mensura omnium notarum qua scilicet unaqueque mensuratur nota: Notarum autem aliae longe, alie breves. Longe, alie longiores, alie longissime. Breves vero: alie breviores, alie brevissime".

("Música mensural es la que conoce la medida de todas las v oces con razón probable; o así: música mensural es la pericia de modular [medir] el sonido y el canto, medida con el tiempo musical. El tiempo, como aquí se entiende, es un sonido diferenciado di visible en tres instantes. El instante como aquí se entiende, es lo mínimo e indi visible, que el oído puede percibir clara y distintamente en el sonido. Lo que también era denominado tiempo por los antiguos. Pero la opinión de los modernos es mejor, porque, a saber, ponen la sucesión en el tiempo musical sujeta al mo vimiento. Pues todos los que transfieren, lo hacen fundándose en alguna semejanza. El tiempo musical ha de tener alguna semejanza con el tiempo natural. Pero, al hablar naturalmente, no encontramos la sucesión, sino en aquellos que están sometidos de algún modo al movimiento. El antes y el después causan la sucesión del tiempo. En tanto numeramos el antes y después en el mo vimiento, captamos el tiempo, que no es otra cosa que el número anterior y posterior en el mo vimiento. Como, por lo tanto, el tiempo musical está sometido al movimiento progresivo [entendido linealmente], es necesario siempre poner en él la sucesión de tres instantes, que suprimen los antiguos, poniendo algo indi visible en el tiempo, a saber, un solo instante. Puede, aunque

proceden de la imaginación, no pertenecen a la música, sino a la astronomía. Pues la música como juzga sobre las cosas sensibles que se perciben por las voces, y no sobre las insensibles, que son producto de la imaginación" (CS IV, 275 b). 
impropiamente, permitirse denominar tiempo al instante del tiempo, como ahora vulg armente se dice, entonces un tiempo es brevísimo: y según esto, al menos se salv a la opinión de los antiguos [...] Por lo tanto, este tiempo musical es la medida de todas las notas, con la que se mide cada una de las notas: De la notas unas son long as, otras breves, otras más largas y otras larguísimas. Las breves, realmente, unas son más breves y otras brevísimas"). (CS I, 89 a).

A continuación, J. de Moravia explica las figuras musicales usuales en su época según los antiguos y modernos, teniendo presente la duración de las notas en el canto llano ${ }^{47}$ :

"Figura note longe est quadrata, sed non [?] caudata, ut hec: Figura brevis note est quidem quadrata, sed non caudata, ut hec: Figura semibrevis note nec est quadrata, nec caudata; habet enim e xpansos angulos, que et tesseronata apud quosdam dicitur, ut hec:".

("La figura de la longa es cuadrada, pero sin [?] cauda, como ésta: [dibuja una nota cuadrada negra con plica descendente a la derecha]. La figura de la breve es cuadrada, pero sin cauda, como ésta: [dibuja una nota cuadrada negra sin plica]. La figura de la semibreve no es ni cuadrada ni con cauda, tiene los ángulos anchos, y algunos la denominan romboide, como ésta: [dibuja una nota romboide negra]"). (CS I, 89 b).

"Nota longa, in cantu eclesiastico sumpta, habet et habere debet duo tempora moder norum, resolvendo vero VI tempora antiquorum; longior, tria tempora modernorum, sed IX tempora antiquorum; longissima vero quatuor tempora modernorum, sed XII tempora antiquorum. Item nota brevis, sumpta in cantu ecclesiastico, habet et habere debet unum tempus modernorum, resolvendo vero tria tempora antiquorum; brevior duas instantias modernorum $v$ el duo tempora antiquorum; bre vissima vero unam instantiam modernorum, que quidem, secundum modernos et antiquos, indivisibilis est, vel unum tempus antiquorum. De quibus omnibus tales dantur regule: omnis cantus planus et ecclesiasticus notas primo et principaliter equales habent unius temporis modernorum, sed trium temporum antiquorum, id est breves, exceptis quinque. Prima omnium est a qua unusquisque cantus incipit, que et principaliter dicitur que semper est longa: Si tamen in finali cantus extitit, alia brevis est, ut cetere... [etc.]".

("La longa, tomada del canto eclesiástico, tiene y debe tenerdos tiempos de los modernos, resolviendo VI tiempos de los antiguos; lalongior, tres tiempos de los modernos, peroIX de los antiguos; lalongissima cuatro tiempos de los modernos, peroII de los antiguos Asimismo, labreve, tomada del canto eclesiástico, tiene y debe tener un tiempo de los modernos, resolviendo tres tiempos de los antiguos; la brevior, dos instantes de los modernos o dos tiempos de los antiguos; labrevísima un instante de los modernos, la cual para los antiguos y modernos es indivisible, o un tiempo de los antiguos. De todo esto sacamos las reglas siguientes: todo canto llano y eclesiástico tiene en primer lug ar y principalmente todas las notas iguales equivalentes a un tiempo de los modernos, pero tres tiempos de los antiguos, es decirbreves, exceptuadas cinco. La primera de todas es con la que empieza todo canto, que se llama principal y siempre es long a: Si aparece al final del canto, la otra es breve, como las demás"). (CS I, 90 a).

47 El citado tratadoQuatuor principalia musicae, añade matices sobre la agrupación o articulación de las notas, fundándose en el "accentus": "T empus enim potest dupiciter accipi: primo pro mensura tam v ocis prolatae, quam ejus contrarii, ut superius dictum est, cap. 2. Secundo accipitur pro bre vi recta, ut in isto loco. Et dicitur recta bre vis, ad differentiam alteratae brevis, quia duplex est bre vis, videlicet recta et alterata. Bre vis recta est illud quod est minimum in plenitudine v ocis; plenitudienm dico , propter semibreves et minimas quae prolatae sunt non in plenitudine vocis. Alterata brevis dicitur quae in figura brevis recte se et aliam rectam SUB UNO ACCENTU includit. Item quando semibre vis tres continet in se minimas, tunc dicitur major prolatio; quando vero duas, tunc dicitur minor prolatio" ( CS IV, 262 b); "Sed dico eam esse maximam, eo quod v oci hominis sufficit in cantu mensurabili tam diu [tiempo prolongado] SUB UNO ACCENTU, et cum uno anelitu continuare" (CS IV, 263 a). 
Sobre la semibreve dice, más adelante, lo siguiente:

"Mensurabile est quod mensura unius temporis, $v$ el plurium mensuratur. Ultra mensuram sunt que minus quam uno tempore et amplius quam duobus mensurantur; ut semibreves que sic figurantur".

("Mensurable es lo que se mide con uno o v arios tiempos. Más allá de la mensura, están [las figuras] que se miden con menos de un tiempo o más de dos, como las semibreves, que se figuran así: [dibuja tres figuras negras romboidales]"). (CS I, 94 b).

Aquí, J. de Moravia presenta las siguientes equivalencias ${ }^{48}$ entre la mensura apud antiquos (Escuela de Notre-Dame, siglo XII) y apud modernos (Ars Antiqua, siglo XIII):

$\underline{A P U D}$ ANTIQUOS

LONGISSIMA $^{49}$

XII tempora Quatuor

[12 breves: 6 longas: 3 máximas]

LONGIOR

IX tempora Tria
APUD MODERNOS

LONGISSIMA

tempora [4 breves perfectas]

[4 breves: 2 longas: 1 máxima]

LONGIOR

[= brevis apud antiquos]

tempora [3 breves perfectas]

48 Es interesante comparar, en este aspecto, a J. de Moravia con su contemporáneo Jacobus Leodiensis (Speculum Musicae; CS II, 408 a y b). Este último tratadista dice, que un cierto doctor de su época (París, 1330c [= J. de Muris]), enseñaba las siguientes partes prolationis: maxima, longa, bre vis, semibrevis et minima; y las siguientes mensuras: Longissima: "Que est que sub uno accentu tribus longis temporibus mensuratur" (Longissima = 3 longas). Longior: "Que sub uno accentu duobus longis temporibus mensuratur" (longior = 2 longas). La longior es bipartita: a) Longa perfecta: "Que sub uno accentu ter [per?] tria tempora brevia mensuratur" (longa perfecta = tres bre ves; [señales, según Bartolomé Ramos de P areja: “O3 ó O2”]); b) Longa imperfecta: “Que sub uno accentu per duo tempora bre via mensuratur" (longa imperfecta = dos bre ves; [señales, se gún Ramos de P areja: "C2 ó C3”]). La LONGA SIMPLEX (CS II, 408 b) puede ser: a) Perfecte perfecta (longa perfecta = 3 breves y, cada breve, 3 semibreves: [señal, según Ramos de P areja: “O3”]); b) Imperfecte perfecta (longa imperfecta = 3 bre ves y, cada bre ve 2 semibre ves: [señal, se gún Ramos de Pareja: "O2”]); c) Perfecte imperfecta (longa imperfecta = 2 breves y, cada breve 3 semibreves: [señal, según Ramos de Pareja: “C3”]); d) Imperfecte imperfecta (longa imperfecta = 2 bre ves y, cada breve, 2 semibreves [señal, según Ramos de Pareja: “C2”]). Obsérvese aquí la constante alusión al accentus. Un poco antes, este mismo tratado, dice lo siguiente respecto al modo de dirigir la mensura: "Sed moderni nunc morosa multum utuntur mensura; tantum enim apud modernos valet nunc brevis perfecte tertia pars quam apud antiquos brevis perfecta, quia tan morose mensuratur ut illa, et tantum bre vis perfecta quantum apud veteres longa perfecta" ("Pero, ahora los modernos usan mucho la mensura amororsa; pues ahora $\mathrm{v}$ ale tanto la tercera parte de una bre ve perfecta de los modernos como una breve perfecta de los antiguos, porque la miden con tal morosidad como aquella, y vale la breve perfecta como la longa de los antiguos") (CS II, 400 b - 401 a). El contenido de este último texto coincide con lo expuesto en la tabla comparativa de la duración de las notas "apud antiguos" y "apud modernos". Los modernos dabara la semibreve la misma duración que daban los antiguos a la breve. También, en este mismo sentido, el contenido del ANóNImo VI. De musica mensurabili (Cs III, 400 b), revela una situación transitoria entre Juan de Garlandia/Franco de Colonia y Juan de Muris, es decir, hacia el año 1300. El tratadista aplica a la notación modal las cantidades o prolaciones de Juan de Muris. Parte de Magister Johannes de Muris, al que cita. Según este tratado, se pueden combinar las diferentes cantidades y mezclar los modos (a los modos pueden asignarse cinco maneras de cantar). Según este tratado existen cuatro grados (cantidades) de mensura:Aunque la directio mensurae se realiza de tres maneras: "a la longa" ( $2^{\circ}$ grado); "a la bre ve" (3er. grado), y "a la semibre ve" ( $4^{\circ}$ grado). 1er. grado: relación longissima / longa: LONGISSIMA (= 3/3 ó 81 mínimas) -longior (2/3 ó 54 mínimas) - longa (1/3 ó 27 mínimas). ${ }^{\circ}$. grado: relación longa / brevis: [LONGA] PERFECTA (= 3/3 ó 27 mínimas) - imperfecta (2/3 ó 18 mínimas) brevis (=1/3 ó 9 mínimas).3er. grado: relación brevis / semibrevis: BREVIS (=3/3 ó 9 mínimas) - brevior (=2/3 ó 6 mínimas) - brevissima (= 1/3 ó 3 mínimas). $4^{\circ}$. grado: relación semibrevis / minima: [semibrevis-] PARVA (=3/3 ó 3 mínimas) - minor (=2/3 ó 2 mínimas) - minima (=1/3 ó 1 mínima). [La UNIDAD más pequeña para computar las longitudes o duraciones de cada una de las figuras o cantidades, etc. es la mínIMA]. [4 ${ }^{o}$ grado: 1 mínima - 2 mínimas - 3 mínimas (1 x 3 =3: Semibreve). 3er. grado: 3 mínimas - 6 mínimas - 9 mínimas (3 x 3 -9: Breve). $2^{\circ}$ grado: 9 mínimas - 18 mínimas - 27 mínimas (9 x 3 = 27: Longa). ler. grado: 27 mínimas - 54 mínimas - 81 mínimas ( 27 x 3 = 81: Maxima].

49 Sobre las denominaciones positiva, comparativa y superlativa de las notas [longa-longior-longissima / brevis-breviorbrevissima] véase, al respecto: -T HEODORICO DE CAMPo [ $f$ l. mediados del siglo XIV]: De musica mensurabili [CS III, 179 a]. Cfr.: Wolf, Johannes: Geschichte der Mensural- Notation. Hildesheim, Georg Olms, 1965 [Leipzig, Breitkopf \& Härtel, 1904$]$, p. 79. 
[9 breves: 3 longas: 1 máx.]

LONGA

VI tempora Duo

[6 breves: 2 longas perfectas]

BREVIS

Tria tempora

Unum

[3 breves: longa perfecta]

BREVIOR

Duo tempora Duae

[2 breves: longa imperfecta]

BREVISSIMA

Unum tempus Una

[breve: tiempo mínimo]

[breve: unidad de medida] [longa perfecta]

LONGA [= brevior apud antiquos]

tempora [2 breves perfectas]

[longa imperfecta]

BREVIS [= brevissima apud antiquos]

tempus [breve perfecta]

[3 instantiae: breve perfecta]

BREVIOR

instantiae [2 instantes]

[2 instantiae: breve imperfecta]

BREVISSIMA

instantia [1 semibreve]

[semibreve: tiempo mínimo]

[semibreve: unidad de medida]

Como vemos en esta tabla comparati va, la duración (movimiento) de las figuras musicales de los antiguos (apud antiquos) se había ralentizado el triple en los modernos ( apud modernos). Es decir, si, anteriormente, la unidad de mensura era la longa perfecta, ahora es la breve [también perfecta] (1/3 de longa).

De ahí, el siguiente texto de Jacobus Leodiensis [Jacques de Lieja] (Speculum Musicae; CS II, 401 a):

"Sed moderni nunc morosa multum utuntur mensura; tantum enim apud modernos $\mathrm{v}$ alet nunc bre vis perfecte tertia pars quam apud antiquos bre vis perfecta, quia tan morose mensuratur ut illa, et tantum valet brevis perfecta quantum apud veteres longa perfecta".

("Pero, ahora los moderos usan mucho la mensura morosa; pues ahora vale tanto la tercera parte de una breve perfecta de los modernos como una bree perfecta de los antiguos, porque la miden con tal morosidad como aquella, y vale tanto la breve perfecta como la longa de los antiguos"). (CS II, 400 b- 401 a).

El contenido de este te xto coincide con lo e xpuesto en la tabla comparati va de la duración de las notas apud antiquos y apud modernos de J. de Moravia:

La longissima de XII tiempos, según los "antiguos", equivale a una longissima de IV tiempos de los "modernos" (máxima) (xII : 3 = IV)

La longior de IX tiempos de los antiguos equi vale a una longior de III tiempos de los modernos (longa perfecta) $(\mathrm{IX}: 3=\mathrm{III})$.

La longa de VI tiempos de los antiguos equi vale a una longa de II tiempos de los modernos (longa imperfecta) $(\mathrm{VI}: 3=\mathrm{II})$.

La breve de III tiempos ( 9 semibre ves) de los antiguos equi vale a una breve de I tiempo de los modernos (breve perfecta) (IX : $3=$ III semibreves). 
La brevior de II tiempos (6 semibre ves) de los antiguos equi vale a una brevior de II instantiae (semibreves) de los modernos (breve imperfecta) (vi semibreves : $3=$ II semibreves o breve imperfecta).

La brevissima de I tiempo (breve: unidad de medida) de los antiguos equivale a la brevissima de una instantia (semibreve: unidad de medida) de los modernos (I breve : $3=1 / 3$ de breve o semibreve).

Es de interés saber, que la medida común oduración constante, esencial para poder comparar ambas medidas, está tomada del canto llano:

"Nota longa, in cantu eclesiastico sumpta, habet et habere debet duo tempora modernorum, resolvendo vero vI tempora antiquorum" o "Item nota bre vis, sumpta in cantu ecclesiastico, habet et habere debet unum tempus modernorum, resolvendo vero tria tempora antiquorum".

("La nota long a, tomada del canto eclesiástico" o " Asimismo la nota bre ve, tomada del canto eclesiástico"). (CS I, 90 a).

Los teóricos de la época, al tratar del canto llano, afirman que fluye se gún la cantidad continua (inmensurable), lo que no quiere decir , que todas las notas teng an "igual valor", ya que, por otro lado, todos ellos hablan de una diferencia temporal entre notalonga (2 tiempos) y breve (1 tiempo). Esto indica, que, en el canto llano (música continua) existían dichas diferencias y se sentían "interiormente", porque estaban grabadas en la "memoria", y así se transmitían ${ }^{50}$ de unas generaciones a otras.

Son de gran interés las observaciones de JUAn de Grocheo (1300c), en el tratado De musica ${ }^{51}$, sobre el canto llano ${ }^{52}$ y la música mensural:

"Alii autem musicam di vidunt in planam si ve inmensurabilem et mensurabilem, per planam si ve inmensurabilem intellegentes ecclesiasticam, quae secundum Gregorium pluribus tonis determinatur. Per mensurabilem intellegunt illam, quae ex diversis sonis simul mensuratis et sonantib us efficitur, sicut in conductibus et motetis. Sed si per immensurabilem intellegant musicam nullo modo mensuratam, immo totaliter ad libitum dictam, deficiunt, eo quod quaelibet operatio musicae et cuiuslibet artis debet illius artis $\mathbf{r}$ egulis mensurari. Si autem per immensurabilem non ita praecise mensuratam intellegant, potest, ut videtur, ista di visio remanere. [...] P artes autem musicae plures sunt et di versae secundum diversos usus, diversa idiomata vel diversas linguas in civitatibus vel regionibus diversis".

("Otros, en cambio, di viden la música en llana o inmensurable y mensurable; por [música] llana o inmensurable entienden la eclesiástica, que se gún Gre gorio [Magno] consta de numerosas notas. Por mensural, entienden la que consta de muchos sonidos medidos, que suenan, a la $\mathrm{v} \quad$ ez, como en los conductus y motetes. P ero si se entendiera por inmensurable aquella música, que no se mide de

50 Cfr. texto anteriormente citado de la Commemoratio brevis (GS I, 228).

51 -Grocheo, Johannes de: De musica. -Rohloff, Ernst: Der Musiktraktat des Johannes de Grocheo nach den Quellen neu herausgegeben mit Übersetzung ins Deutsche und Revisionsbericht. Leipzig, Gebrüder Reineck e, "Media latinitas musica, vol. 2", 1943, pp. 41-67.

52 Sobre la medida del canto llano, cfr.: Speculum Musicae (CS II, 303 a): “ Alia est mensura temporalis [...] attendit certam et determinatam temporis morulam [...] alia que mensuram aliquam supra $\mathrm{v}$ oces et successi ve prolatas inspicit ut quod una morosius decantetur quam alia. Et hec ad cantum pertinere potest planum". ("Otra es la medida temporal [...] que se atiene a una tardanza del tiempo cierta y determinada [...], otra es la que se atiene a alguna medida de las $\mathrm{v}$ oces sonantes emitidas sucesivamente, para que una se cante mas lenta que otra. Y ésta puede pertenecer al canto llano"). 
ningún modo, es decir, que se canta siempre a capricho, se equivocan, ya que cualquier realización (operatio) musical, como la de cualquier arte, debe ser medida según exigen sus propias reglas . Si, en cambio, se entiende como inmensurable, aquella que no se mide con medida pr ecisa, entonces, como se v e, puede mantenerse, esta di visión [...] Muchas son las partes [especies, tipos] de música y, diversas, según los diferentes usos, diferentes idiomas o diferentes lenguas, en diferentes ciudades o regiones") ${ }^{53}$.

Grocheo afirma que no existe música inmensurable. El canto llano dispone de su propia medida, es decir, se somete a las reglas propias de su arte.

Las duraciones básicas (sentidas o grabadas en la memoria) citadas, que servían de referencia al interpretar el canto gregoriano (música continua) y lapolifonía (música discreta), pueden ayudar a hacerse una idea sobre la duración de la longa (sílaba longa) o la breve (sílaba breve) en la música mensural de aquella época. También como punto de referencia para medir (ordenar el morimiento), los teóricos hablan del plausus y del pulsus venarum (latido del corazón).

A finales del siglo XIII, con la aparición del nue vo concepto de tiempo (físico) como "mo vimiento continuo", divisible "ad infinitum", se ve la necesidad de definir con mayor precisión eltempus musicum, para fijar con precisión el movimiento (igual o desigual) de las diversas voces, que forman el conjunto polifónico.

J. de Grocheo distingue eltempus per se (fenómeno físico, movimiento continuo, circular) deltempus musicum, que define como aquello que se realiza en el tiempo (sobre el tempus, cfr. CS I, 89 a, ss.). El tiempo (mensura motus: unidad, la breve), empieza ahora a considerarse comoun instante, equivalente en duración a la pronunciación de una sílaba (breve). Un instante es el mínimo espacio de tiempo captable, es decir, racionalmente (matemáticamente) formulable. Y, para definirlo, era necesario el punto de apoyo o unidad, grabada en la memoria; de ahí, que se hable de su relación con el ímpetu del lenguaje (acento) o con el pulso de las venas.

De estos temas se ocupa también el Speculum musicae de Jacobus Leodiensis [JaCQues de Lieja] (CS II, 303 b), contemporáneo de J. de Moravia. Este tratado habla, en primer lugar, del ritmo del accentus (canto llano silábico), al indicar que existe gran semejanza entre el acento de la dicción (lenguaje) y los modos de cantar los salmos:

"Cum igitur antiqui Latini consonantiam quamdam in musica tantummodo tonum v ocant, gramatici etiam accentus dictionis tonos nominare ceperunt. Latini cantores non parv am esse similitudinem inter accentus prosaice locutionis modosque psallendi v el cantandi. Considerantes nomen hoc utriusque commune esse sanxerunt".

("Si, por lo tanto, los antiguos latinos denominan tono a cierta consonancia en la música, lgsamáticos empezaron a denominar también tonos al acento de la dicción. Los cantores latinos dicen que no es poca la semejanza entre el acento de la dicción en prosa y los modos de cantar salmos. Considerando esto, sancionaron que este nombre era común a ambos"). (CS II, 241 b).

53 -R oHLOFf, Ernst: Der Musiktraktat des Johannes de Grocheo..., op. cit., p. 47). 
Después, al tratar de la "mensura" en elcanto llano, la cual "mira las voces sucesivamente emitidas, para que una se cante más despacio que otra" (voces et successive prolatas inspicit ut quod una morosius decantetur quam alia) (cs II, 303 b), explica diversas maneras de proferir las notas teniendo presente el texto, de modo que, "quien ignora el canto llano, en vano aspira al mensural":

"Et hec ad cantum pertinere potest planum, nam secundum Guidonis doctrinam [...] Quedam morose in quibus prolixior [más largo] cadit temporis morulam respectu aliarum admodum syllabarum longarum respectu brevium, ut voces penultimae ante pasusas et ultime, nisi forte in psalmodia, in qua communiter ultime debent esse subitae et sine protractione [...] Qui igitur cantum ignorat planum, frustra tendit ad mensuratum. Prius enim in cantu plano se debet quisque fundare: de hinc ad mensurabilem potest accedere".

("Y esto puede pertenecer al canto llano, pues se gún la doctrina de Guido [...] Unas [notas] se cantan más lentas, en las que la mora (tardanza) del tiempo es más lar ga respecto a las otras, a la manera de las sílabas largas respecto a las bre ves; las notas penúltimas y últimas antes de las pausas, a no ser en la salmodia, en la cual las últimas deben ser rápidas y sin alar gar [...] Quien ignora el canto llano, en vano aspira al mensural. Todos, pues, deben fundarse antes en el canto llano, y de ahí puede acceder al mensural"). (CS II, 303 b).

Los teóricos informan sobre la paulatina aparición de figuras musicales menores en duración (brevis, brevior, brevissima, minima, etc.). La dirección de la mensura pasa de basarse en la longa como unidad, a la breve. Para comprender mejor las equivalencias de medida en la práctica musical de los antiguos y modernos, puede ayudar también el estudio de logradus crescendi o decrescendi("grados de aumentación o disminución") de las notas y de la medida musical. Sobre estas equivalencias entre los grados de mensura, tratan diversos teóricos de la época como el citado Speculum musicae de Jacobus Leodiensis [Jacques de Lieja], ya que compara la dirección de la medida entreapud antiquos (Petrus de Cruce [Pierre de la Croix (*1270c; †1347a) ]) y apud modernos (J. de Muris o Ars Nova). (CS II, 417-419).

Respecto a este tema, Simón [De] Tunstede [DE Norwich] (*1310c; †1369) ( Quatuor principalis musicae; cS IV, 274) dice lo siguiente:

"Decrescit v ero a majore [3] per minorem [2] ad minimam [1]; namque ubicumque est numerus ternarius, ibi est major et ubi binarius, ibi minor et ubi unitas ibi est et minima, quia ista conertuntur. Sed notandum est quod unitas dupliciter potest considerari, videlicet prout est quantitas, et sic potest di vidi, aut prout est quantitatis principium; et sic manet indivisibilis. Primus gradus crescendi ad perfectionem, a minima prolatione vocis incipit, procedendo per semibre vem imperfectam, ad semibrevem perfectam. Secundus vero gradus crescendi ad perfectionem, incipit a semibrei, procedendo per brevem imperfectam duas in se continentem semibreves, ad brevem perfectam. Tertius enim crescendi gradus ad perfectionem, incipit a bre vi recta que est minimum in plenitudine $\mathrm{v}$ ocis, procedendo per long am imperfectam, duas breves ejusdem naturae in se continentem, ad longam perfectam. Sicque gradatim potest ascensus fieri in infinitum incipiendo a primo gradu, sed nunquam ad ultimum crescendi gradum pervenitur".

("Disminuye desde la mayor [3/3], por la menor [2/3], a la mínima [1/3]; pues donde está el número ternario allí está el mayor, y donde el binario, allí el menor , y donde la unidad, allí la mínima, porque estas se recon vierten. Pero se ha de observ ar que la unidad puede considerarse doblemente, a saber , 
como cantidad, que puede ser di vidida, o como principio de cantidad, que permanece indi visible. El primer grado de crecer hacia la perfección, empieza desde la mínima prolación de la voz, siguiendo la semibreve imperfecta, hasta la semibre ve perfecta. El se gundo grado de crecer hacia la perfección, empieza en la semibre ve, pasando por la bre ve imperfecta, que contiene dos semibre ves, hasta la bre ve perfecta. El tercer grado de crecer hacia la perfección, empieza en labreve recta, que es lo mínimo en la plenitud de la voz, procediendo por la longa imperfecta, que contiene dos breves de la misma naturaleza, hasta la long a perfecta. Y así gradualmente se puede ascender infinitamente, empezando en el primer grado, pero nunca llegando al último grado"). (CS IV, 274 a).

I.- Primus gradus crescendi ad perfectionem [Primer grado de aumentar hacia la perfección]: Desde la minima (1/3), por la semibrevis imperfecta (2/3), hasta la semibrevis perfecta (3/3). (Semibrevis perfecta $=3$ mínimas)

II.- Secundus gradus crescendi ad perfectionem [Segundo grado de aumentar hacia la perfección]: Desde la semibrevis (1/3), por la brevis imperfecta (2/3), hasta la brevis perfecta (3/3). (Breve perfecta $=3$ semibreves)

III.- Tertius gradus crescendi ad perfectionem[Tercer grado de aumentar hacia la perfección]: Desde la brevis recta (1/3), por la longa imperfecta (2/3), hasta longa perfecta (3/3). ( Longa perfecta $=3$ breves)

Sobre la disminución de los motetes ( De diminutione motettorum), véase también J. de Muris ( CS III, 58).

Sobre las notas, en las que hay que apo yarse, al dirigir el canto polifónico, Simón [de] Tunstede ofrece las siguientes posibilidades:

"Denique in modulando musicam mensurabilem quae discreta dicitur, talis mensura pronuntiari debet, ut"

("Por último, al medir la música mensural, denominada discreta, debe pronunciarse tal medida, como sigue:")

"[1] in tempore perfecto de majori prolatione ingredi possent tantum novem minimae ».

("En el tiempo perfecto con prolación mayor, sólo pueden entrar nueve mínimas").

"[2] In tempore vero imperfecto de majori prolatione, sex minimae habent intrare et non plures ».

("En el tiempo imperfecto con prolación mayor, han de entrar seis mínimas y no más").

"[3] Item, tempus perfectum de minori prolatione ita habet mensurari, ut sex minimae in eo ingredi possent".

(“En el tiempo perfecto con prolación menor, entran seis mínimas").

"[4] Item, tempus imperfectum de minori prolatione tantum quatuor minimas obtinet".

(“En el tiempo imperfecto con prolación menor, entran cuatro mínimas"). (cS IV, 277 b).

Existen, por lo tanto, cuatro maneras de dirigir la medida, basándose siempre en la breve:

1) A la breve perfecta con prolación mayor (3 semibreves ó 9 mínimas $=\mathrm{O}$ [círculo] con un punto dentro, o prolación mayor); 
2) A la breve perfecta con prolación menor (3 semibreves ó 6 mínimas $=\mathrm{O}$ [círculo] sin punto, o prolación menor);

3) A la breve imperfecta con prolación mayor ( 2 semibreves ó 6 mínimas $=\mathrm{C}$ [semicírculo] con un punto dentro, o prolación mayor); y

4) A la breve imperfecta con prolación menor (2 semibreves ó 4 mínimas = C [semcírculo] sin punto, o prolación menor).

El mismo tratado (CS IV, 276-277) se ocupa de la aequipollentia (equivalencia) entre modos, tiempos y prolaciones. Por ejemplo:

Hay equi valencia entre el tiempo perfecto con prolación menor (señal O: 6 mínimas) y el tiempo imperfecto con prolación mayor (señal C con punto dentro: 6 mínimas).

No hay equi valencia, sin embar go, entre cantar cuatro mínimas en una voz contra tres en otra (proporción sesquitercia 4/3); pues, aunque lo permita el oído, va contra la razón. No obstante, suele hacerse por habilidad de los cantores.

Ahora bien, si una v oz canta a la breve perfecta con prolación menor (=3 semibre ves ó 6 mínimas: señal O) y, otra, a la breve imperfecta con prolación mayor (= 2 semibre ves ó 6 mínimas: señal C con punto dentro), esto está de acuerdo con la razón, ya que hayaequipollentia entre ambas medidas, es decir, existe la misma cuantidad (6 mínimas) en ambas voces.

El cambio del ternario al binario se indica también por medio del color de la notación. El cambio de color "negro por el rojo", en la notación negra, indica que las figuras perfectas (ternarias) se convierten en imperfectas (binarias). O el cambio de color "blanco por ne gro", en la notación blanca, indica el cambio del ritmo binario al ternario (dos breves blancas perfectas equivalen a tres breves negras imperfectas).

Estos importantes matices o posibilidades de plasmar en la notación el "ritmo suelto" del lenguaje, recuerda a San Agustín, cuando habla de combinar el coreo o troqueo (longa-breve) con el yambo (brevelonga), dando por resultado elcoriyambo (longa-breve/breve-longa), es decir, de la posibilidad de articular la medida en dos partes ternarias: longa-breve / breve-longa o en tres binarias: longa /breve-breve / longa.

Estas combinaciones rítmicas, muy usadas en la historia de la música occidental, son conocidas como la hemiolia maior (tres breves negras binarias o imperfectas, que alternan o se combinan con dos breves blancas ternarias o perfectas), o la hemiolia minor (tres semibreves negras o binarias, que alternan o se combinan con dos semibreves blancas o ternarias).

Dichas posibilidades de combinar o alternar, dentro de la medida cierta, grupos binarios con ternarios, indica, que, en el fondo, dichapráctica disponía de los elementos necesarios, para expresar la enorme riqueza del ritmo suelto del lenguaje, es decir, del acento. De ahí, que las verdaderas señales de medida no sean sólo las externas de modo, tiempo y prolación $(\mathrm{O} 3, \mathrm{O} 2, \mathrm{O}, \mathrm{C}$, etc.), extrínsecas o accidentales de la notación mensural, sino las intrísecas o esenciales (perfección, imperfección de figuras, color, silencios, etc.).

Recibido: 20/05/2009

Aceptado:

10/07/2009 